\title{
Utilizing Two-Dimensional Gas Chromatography Time of Flight Mass Spectrometry (GCxGC ToFMS) to Characterize Volatile Products from Pyrolysis of Living Vegetation Foliage
}

Roderquita K. Moore, ${ }^{\mathrm{a}, *}$ Mark A. Dietenberger, ${ }^{\mathrm{a}}$ Doreen H. Mann, ${ }^{\mathrm{a}}$ Patricia K. Lebow, ${ }^{\mathrm{a}}$ and David R. Weise ${ }^{\mathrm{b}}$

Wildland fire can cause significant damage but is also a natural process that is key to the healthy functioning of many ecosystems worldwide. Primary fuels for a wildland fire are the dead foliage and small branches which accumulate as litter on the ground. A cone calorimeter was used to measure the various aspects of these fuels. A single sample of preignition gases from the live leaves of seven plant species were vacuum collected on quality filters and within super-chilled solvent mixtures. GC-TOFMS (1D) and GCxGC-TOFMS (2D) were used to characterize the "white" smoke emissions. The vegetation chemicals were separated into 4 categories: hydrocarbons $(\mathrm{CH})$, oxygenated organics $(\mathrm{CHO})$, unknown peaks (UNK), and organic non-metals (ONM). The multivariate paired Hotelling $\mathrm{T}^{2}$ test determined that the composition of the white smoke as described by the relative number of peaks in the four chemical groups differed significantly between $1 \mathrm{D}$ and $2 \mathrm{D}$ (Prob $>\mathrm{F}_{3,4}=0.00004$ ). In contrast, the relative peak area percentages in the four chemical groups did not differ between 1D and 2D (Prob $>F_{3,4}=0.1258$ ). The Molecular Chemical Maps (MCMs) were used to identify chemical trends between the known and unknown chemicals in live oak and longleaf pine. Application of the 2D technique may provide more detailed information necessary to improve the numerical modeling of wildland fire behavior and emissions production.

DOI: 10.15376/biores.17.1.862-889

Keywords: GCxGC TOFMS; Molecular chemical mapping; Live fuel properties; Wildfire smoke

Contact information: a: USDA Forest Service, Forest Product Laboratory, One Gifford Pinchot Drive, Madison WI 53726; b: USDA Forest Service, PSW Research Station, Fire and Fuels Program, Riverside, CA 92507; *Corresponding author: roderquita.k.moore@usda.gov

\section{INTRODUCTION}

In the United States for the last 10 years there have been an average of 7.5 million acres burned by 71,950 fires, causing loss of life and significant damage to structures (Butry et al. 2001; Kukhar et al. 2020). The smoke generated by these fires can usually be seen from outer space, is a major human health concern, and has significant impact on the atmosphere. Similarly, in many locations, fires have released energy at rates higher than the current vegetation is adapted to, potentially causing long-term effects including soil loss, conversion to other vegetation types, loss of plant and animal habitat, and decreased water quality. Prescribed burning can be an effective tool to reduce hazardous fuel loads, which decreases the risk of larger fires while providing ecological benefits; however, it 
produces smoke, which is regulated in the United States by the Clean Air Act and its amendments (Martin and Dell 1978; Green 1981; Waldrop and Goodrick 2012; National Wildfire Coordinating Group 2018).

The burning of vegetation is a complex phenomenon (Bytnerowicz et al. 2009) composed of two main processes - pyrolysis (thermal decomposition) and combustion (oxidation), which are still not well-described even after a century of study. Pyrolysis of the solid material (vegetation) produces gases and a solid material called char. The gases can react (combust) with oxygen, producing a flame. The char can also combust. Lignin, cellulose, and hemicellulose are the major components of vegetation. In live plants, pyrolysis (Shafizadeh 1968; Yokelson et al. 1996; Ward 2001; Dietenberger et al. 2020) includes several stages: (1) evaporation of water, (2) distillation of terpenes and light volatile organic carbons (VOCs), (3) pyrolysis of aboveground plant parts (foliage, stem, bark) (Matt et al. 2020) with associated chemical reactions that produce volatiles such as VOCs, trace gases, tar, and particles, and (4) charring of these same plant parts. Pyrolysis of belowground parts (roots) may also occur under certain ground fire settings (e.g. Rein 2013). The pyrolysis process of these components is complex and temperature dependent (Neves et al. 2011). Furthermore, there are two main zones of combustion, the first within the flame sheets of the diffusion flame that partially or entirely capture the volatiles and react them with entrained air, and the second within the organic char layer where the penetrating air oxidizes the char interior surfaces. Therefore, emissions contain a large component of uncombusted gases and aerosols (grouped as volatiles) as sourcing from pyrolysis that circumvent the combustion zones or partake in inefficient combustion processes (Yokelson et al. 1997; Leonellia et al. 2017; Barboni et al. 2020).

The VOC formation mechanism is temperature dependent (Sekimoto et al. 2018; Yokelson et al. 1996, 1997; Zhao et al. 2017). The depolymerization of lignin occurs in a low temperature range of 300 to $500{ }^{\circ} \mathrm{C}$. The degraded lignin monomers consist of substituted methoxy compounds such as guaiacols, isoeugenol, and syringols. The cellulose and hemicellulose temperature ranges for depolymerization are 300 to $400{ }^{\circ} \mathrm{C}$. There are several reactions occurring simultaneously that emit VOCs, for example hydroxyacetone, acetaldehyde, and acetic acid, during fragmentation from the depolymerization of cellulose and/or hemicellulose. During pyrolysis of biopolymers, VOC emissions are equally distributed during low and high temperatures. The concentration of chemicals may vary as temperature increases. The release of oxygenated compounds increases carbon content in the solid fuel, which contributes to the strong bonds present in char. Aromatization of nonsubstituted and polycyclic aromatic hydrocarbons (PAHs) increases during high temperatures. The functional groups represented in the hightemperature profile are alkenes, alkynes, dienes, PAHs, nitriles, amides, nitrites, nitrates, and thiols/sulfides. The low-temperature functional groups are alcohols, ketones, acids, methoxy groups, esters, and amines. Description and measurement of the chemistry of pyrolysis and combustion is challenging because it is dynamic and requires multiple instruments to measure the many compounds. While numerous instruments have been used effectively, spatial, temporal and chemical resolution of measurements continues to be a challenge. Application of instruments capable of high-resolution measurements under tightly controlled combustion experiments applied to the chaotic conditions associated with the diffusion flames of a wildland fire is also a challenge, but this may yield information not previously known. Over the past decade, several instrument intercomparisons have been performed to identify and compare various components of smoke (Christian et al. 2004; von Bobrutzki et al. 2010; Warneke et al. 2011; Li et al. 2019). More 
characterization and quantitative comparison are needed to better understand VOCs and primary organic aerosols.

Smoke emissions from fires can be grouped into (A) air-borne particles, known as brown carbon (organic carbon or aerosols) and black carbon (soot) (Olson et al. 2015; Leonellia et al. 2017), (B) high molecular weight organic compounds, known as heavy tar (condensable on filters) and light tar (condensable in cooled solvent) (Leonellia et al. 2017; Knorr et al. 2019), (C) fuel gases (particularly methane and other VOCs) (Yokelson et al. 1996), and (D) combustion gaseous products such as $\mathrm{CO}_{2}, \mathrm{CO}$, and $\mathrm{H}_{2} \mathrm{O}$. Indeed emissions A-D have suggested common measurement methods, such as non-dispersive infrared (NDIR) used for combustion gases, Fourier transform infrared (FTIR) used for fuel gases, gas chromatography mass spectrometry (GC/MS) used for light tar (or bio-oil), and laser light extinctions or impactors used for brown and black carbon. However, a significant amount of emission mass is still unaccounted for by these particular measurement methods, particularly for smoldering, which may be due to undetected or unidentified aerosols and tar as sourced from the primary pyrolysis volatile products of condensed matter, such as that of forest litter, live foliage, and wood.

There are several existing smoke emission repositories containing information from the field and laboratory of wildland fires. While emissions measurement has occurred for the past 50 years, the repository lacks diversity among vegetative fuel sources; more data exists to support flaming combustion, i.e., wildfire and, prescribed burning (Prichard et al. 2020). This lack of diversity may hinder prediction for the emissions of pollutants. More studies are needed for all pollutants in the area of wildfires, residual smoldering and organic soils, and specific vegetation types, including grasslands, northern forests and broadleaf deciduous forests. Certain trace gases and aerosols such as non-methane organic compounds (NMOCs) were underrepresented. The limited detection of trace aerosols or NMOCs are because of detection sensitivity and the resolving power of the instrumentation (Moore et al. 2015a,b, 2017a,b,c).

Yokelson et al. (2013) investigated the quantitative measurements on NMOCs emissions. During this investigation, it was discovered that approximately $72 \%$ of NMOCs emitted by some fuel types were unidentified using the current technology. The emission gap of NMOC limits the possibility of discovering the impact of biomass burning on the atmosphere, modeling the impact of the local to global chemistry of both natural and anthropogenic fires, and developing preventative solutions to deactivate chemicals that contributes to the formation of ozone $\left(\mathrm{O}_{3}\right)$ or organic aerosols. Most of the unidentified species have molecular mass greater than $90 \mathrm{~m} / \mathrm{z}$ and thus may be semi-volatile or of intermediate volatility. State of the art instrumentation was used such as: open-path Fourier transform infrared (OPFTIR) spectrometer, proton-transfer-reaction mass spectrometry (PTR-MS), proton-transfer ion-trap mass spectrometry (PIT-MS), negative-ion protontransfer chemical-ionization mass spectrometry (NI-PT-CIMS), and gas chromatography with MS detection (GC-MS). However, efforts to better characterize the chemistry and oxidation products of the species with high resolution mass spectrometry is still needed for complete mass balance characterization of organic trace gases and investigation of the effects of oxidation, temperature, and humidity on full mass scans.

Several analytical instruments have been used to characterize vegetation smoke emissions. GC/MS is often used; however, GCxGC is expected to provide an enhanced separation (typically one to two orders of magnitude) compared with one-dimensional GC. GCxGC uses a two-tandem column set that has two different stationary phases to separate complex mixtures. The chemical phases (column packing) of these columns are nonpolar 
for the $1^{\text {st }}$ dimension and semipolar for the $2^{\text {nd }}$ dimension. The samples are injected into the first column and travel to a thermal modulator with cryogenic jets and are then injected into the second-dimension column (Liu and Phillips 1991). The separation power of this technique has the potential to classify known and unknown compounds through chromatographic retention patterns.

When coupled with time of flight mass spectrometry (TOFMS), this technique will allow constituents of unresolved complex mixtures to take advantage of continuous full range nonskewed mass spectral information and fast acquisition rates. GCxGC has been successfully applied to a number of complex mixtures such as petroleum (Mao et al. 2009; Kohl et al. 2010), tobacco (Lu et al. 2003), flavors (Bordiga et al. 2009), fragrances (Shellie et al. 2004), essential oils (Dimandja et al. 2000), and metabolic (Welthagen et al. 2005) profiling. These applications have shown that GCxGC is able to separate mixtures that contain up to 10,000 compounds (Dimandja 2004). Panic and Gorecki (2006) characterized trace toxic compounds in the environment. The characterization and identification of complex mixtures increase the discovery of new chemicals for medicinal purposes and may provide solutions to grand challenges that are facing our environment.

Although GCxGC has been applied to the pyrolysis of a dried, ground sample of a grass (Miscanthus giganteum) (Groenewold et al. 2017) and to biomass burning smoke in a limited fashion (Hatch et al. 2015; Jen et al. 2019), to our knowledge the GCxGC TOFMS has not been applied to intact pyrolyzing of live wildland fuels. The sample collection, sample preparation and instrument parameters play a significant role in the characterization of the smoke samples. The present study used a two-phase continuous collection process to assist with lowering temperature of the smoke volatiles in a super chilled solution. The super-chilled solution was used to stop degradation or any high volatiles from escaping. In literature, smoke samples went through desorption, and trapping during sample preparation which requires additional heating before injection.

The aim of this study was to utilize GCxGC TOFMS methodology to characterize primary volatiles generated directly from heating via radiation of a thin layer of foliage in a cone calorimeter (pyrolysis gases). Adapting GCxGC-TOFMS offered an opportunity to characterize pyrolytic emissions from wildland fuels in greater detail. This information, coupled with measurement from related studies (Safdari et al. 2018, 2019, 2020; Amini et al. 2019; Scharko et al. 2019a,b; Phillips et al. 2020) can provide (1) a description of primary pyrolysis volatiles helpful for numerical pyrolysis modeling in the presence of air; and (2) a description of more organic compounds that are unfettered by destruction or changes in the close proximity to hot flames. This paper will identify light tar volatiles and characterize these volatiles through molecular chemical mapping. Analysis of heavy tars and aerosols collected on the filters will be presented elsewhere.

\section{EXPERIMENTAL}

\section{Materials}

Nursery-grown seedlings of seven plant species found in wildland fuel beds in the southeastern United States were shipped to the USDA Forest Service Forest Products Laboratory where they were maintained in a greenhouse until being tested (Table 1). Dichloromethane (80\%) acetone (20\%) solution (labeled as DCM), and tetracosane $99 \%$ were purchased from Sigma-Aldrich (St. Louis, MO, USA), isopropanol (IPA) was purchased from Thermo Fisher Scientific (Waltham, Massachusetts, USA), and dried ice 
was purchased locally to keep the liquids super-chilled during DCM collection of the white smoke.

Table 1. Leaf Type Names, and Moisture Content (MC) of Nursery Plants for the Southern United States

\begin{tabular}{|l|l|l|l|l|}
\hline$\#$ & Common Name & Scientific Name & Type & MC \% Wet Basis \\
\hline S1 & Live oak (LO) & Quercus virginiana & Broadleaf & $57.7 \%$ \\
\hline S2 & Saw palmetto (SP) & Serenoa repens & Palmetto & $61.6 \%$ \\
\hline S3 & Longleaf pine & Pinus palustris & Needle like & $64.3 \%$ \\
\hline S4 & Swamp bay (SB) & Persea palustris & Broadleaf & $54.2 \%$ \\
\hline S5 & Dwarf palmetto (DP) & Sabal minor & Palmetto & $65.3 \%$ \\
\hline S6 & Water oak (WO) & Quercus nigra & Broadleaf & $56.0 \%$ \\
\hline S7 & Yaupon (YP) & Ilex vomitoria & Broadleaf & $61.8 \%$ \\
\hline
\end{tabular}

Note: Moisture content from Matt et al. (2020)

\section{Plant Sample and Preparation}

The same plants were used in this project as in Matt et al. (2020). High heating values as well as gross heat of combustion calculated from elemental composition of the plants were presented in Matt et al. (2020). The living leaf from a plant contains major components such as water, lipids, glucose, fructose, protein, pectin, hemicellulose, starch, cellulose, phenolic compounds, lignin, silicates, and minerals (Raven et al. 1981; Matt et al. 2020). This complexity poses additional challenges to identification of pyrolysis products compared with that of wood. As a live leaf is heated, it begins to emit water vapor and volatiles from the leaf components. Contrary to the assumption made with dead fine fuels that all moisture is volatilized before other volatile products are emitted, live foliage may contain a significant amount of moisture (Table 1) when pyrolysis begins (Fletcher et al. 2007; Prince and Fletcher 2014; Yashwanth et al. 2016; Matt et al, 2020). The leaf typically has structural layers of waxy cuticle, upper epidermis, mesophyll, vein, lower epidermis, and lower cuticle, (Biology Libre texts 2020) that ultimately affect the thermal and mass transports of the heated leaf (Raven et al. 1981). The complexity of a live leaf coupled with the large diversity present in the plant kingdom may require a corresponding complex analysis of plant pyrolytic properties. Mature leaves from a plant were snipped with scissors and placed in a pre-weighed petri dish. After about 3 grams of foliage had been harvested (some plants had multiple leaves that added up to 3 grams), the petri dish was covered, weighed, and delivered promptly to the cone calorimeter. Mature leaves from a plant were snipped with scissors and placed in a pre-weighed petri dish. After about 3 grams of foliage had been harvested (some plants have multiple leaves that add up to 3 grams), the petri dish was covered, weighed, and delivered promptly to the cone calorimeter. In the particular case of longleaf pine needles, the typical lengths (203 to 457 $\mathrm{mm})$ were trimmed to the diameter of the cone calorimeter sample holder $(80 \mathrm{~mm})$, and approximately two or three layers were required to adequately cover the area. Foliage from the other species was processed similarly except for trimming.

\section{Enhanced Cone Calorimetry Method for White Smoke Collection}

Several authors have reported the emission of white smoke prior to ignition, which results from pyrolysis and distillation (Yokelson et al. 1996; Leonellia et al. 2017; Pallozzi et al. 2018). A well-developed method for collecting cigarette smoke for analysis with GCxGC-TOFMS (Knorr et al. 2019) was adapted to capture this white smoke. Key features of the collection technique were a vacuum pump to draw the white smoke through an inert 
GC quality filter to capture the heavy tar and then through two in-series impinging bottles with chilled DCM solution to capture the light tar and condensable combustible gases. Since the cone calorimeter was operated in the unpiloted mode, the leaves were completely consumed by smoldering down to the nil ash mass that started when the pyrolysis commenced as the leaves were drying down to nil ash mass.

An enhanced cone calorimetry test was devised to examine leaf drying and volatile properties closely. The vegetation cone holder and smoke sampler (Fig. 1) was modified by adding six 36-gauge Type $\mathrm{K}$ thermocouples (T/C) to the cone calorimeter data acquisition board. Three thermocouples were laid on the bottom steel mesh that is on the top of the sample holder. The leaves were placed singly in a thin bunched layer on the steel mesh. A leaf was placed over each thermocouple, and the circular exposed area was filled in by the leaf. The remaining three thermocouples were placed on top of the leaves and the top steel mesh was placed on top and was pressed/hooked to the bottom mesh to keep all the leaves flat so that they all received the same irradiance $\left(35 \mathrm{kWm}^{-2}\right)$ from the cone's heater. The sample holder was placed in such a fashion to minimize the impact of the six $\mathrm{T} / \mathrm{Cs}$ on the mass loss measurement. The cone calorimeter was in a waiting mode to begin the test at the selected irradiance.

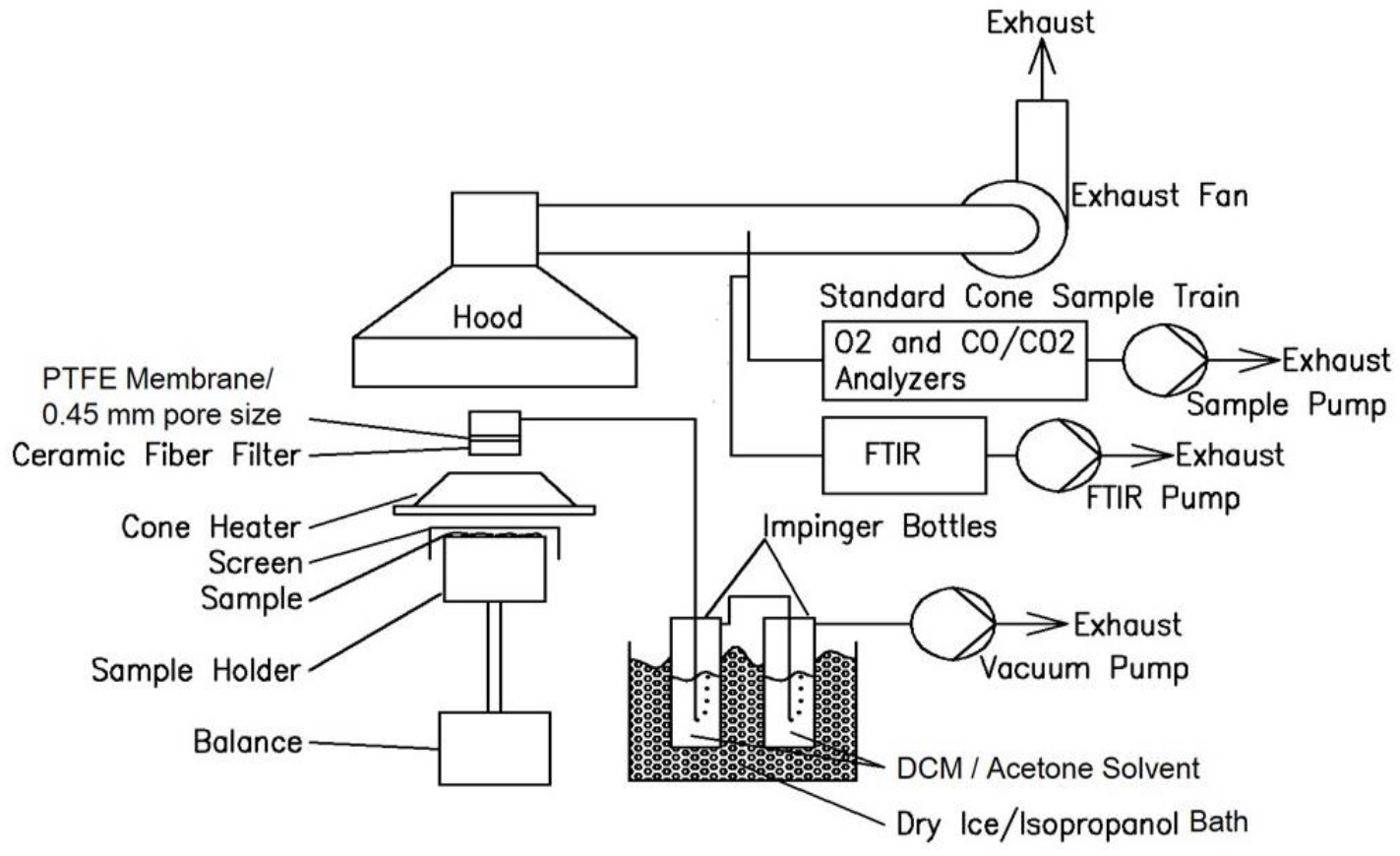

Fig. 1. Enhanced cone calorimeter setup used to capture preignition "white" smoke from live foliage samples

Preliminary testing showed that an irradiance of $35 \mathrm{kWm}^{-2}$ produced temperatures within the leaf of 400 to $600^{\circ} \mathrm{C}$, which have been found to produce maximum yield of tars from the leaf (Amini et al. 2019); these lower temperatures avoid the high-temperature secondary pyrolysis process. The initial radiant heating of the leaves showed a plateau near $100^{\circ} \mathrm{C}$ on both the exposed and shaded side of the leaves, which indicates both moisture desorption and a high thermal conductivity due to the high moisture content of the live leaves. This differs from other temperature profiles reported for single leaves at higher heating rates (Fletcher et al. 2007). After drying, the exposed surfaces (via T/C 
measurements) show a fairly rapid rise up to around $500{ }^{\circ} \mathrm{C}$, thereby initiating both pyrolysis and char oxidation (i.e., smoldering) on the exposed surface at around $200^{\circ} \mathrm{C}$. Meanwhile, the shaded T/Cs had a delayed temperature rise, due to the low thermal conductivity of the dried leaf components. Because of this temperature differential across the leaf thickness, the shaded side could still be evaporating the absorbed water, while simultaneously, the exposed surface could also be emitting water vapor that is primarily from the combustion products of organic char oxidation (e.g., Shotorban et al. 2018).

However, this overlap of water vapor sources appears to be present for a relatively short time interval, such that white smoke was primarily the products of both pyrolysis and organic char oxidation. Furthermore, as the white smoke transitions to the barely visible black smoke at a later degradation time, the leaf residue is undergoing primarily char oxidation, as evidenced by the continuing mass loss and heat release rate and leaf temperatures remaining high. All these processes were measured in the cone calorimeter as mass loss rate and heat release rate as functions of time. During the moisture desorption phase, the cone calorimeter measured leaf mass loss while there were nil measured $\mathrm{CO}_{2}$ and $\mathrm{CO}$ production, nor $\mathrm{O}_{2}$ consumption, nor red laser smoke extinction recorded, but the $\mathrm{H}_{2} \mathrm{O}$ sensor signal was recorded. Therefore, the additional advantage of the $35 \mathrm{kWm}^{-2}$ heat flux exposure was the ability to separate leaf degradation events into the phases of (1) moisture desorption, (2) pyrolysis and char oxidation (white smoke), and (3) char glowing. In the case of longleaf pine live needles, white smoke emitted was thus coming from about $67 \%$ of the leaf dry mass in these tests. This was calculated as initial mass minus moisture mass, and then the dried residue mass was separated into pyrolysis (white smoke source) and char masses. Samples were collected during the appearance of white smoke Because numerous leaves were used per test, abundant white smoke was produced, resulting in an averaged quantity for each test. A total of seven measurements (one per species) was collected.

\section{GC and GCxGC Sample Preparation}

After each calorimetry test, the tubing and impinger bottles were rinsed with IPA. The soiled filters were sealed in separate glass jars and stored in the refrigerator. The smoke samples were filtered, evaporated using a rotary evaporator, and transferred to preweighed vials, sealed, and stored in the freezer. The injections of the smoke samples were removed from the freezer, thawed, spiked with tetracosane (internal standard), mixed, and injected. The tetracosane was used for calibration and alignment analyses. There were several injections done for development of the GC and GCxGC method. However, only two injection data were used. A rotary evaporator was used to dry the samples. The mass of the concentrated samples ranged from 1.5 to $15.4 \mathrm{mg}$. Samples were spiked with tetracosane and dissolved with dichloromethane. National Institute of Standards and Technology (NIST) and Wiley libraries were used to identify the chemicals detected in the samples. Only chemical masses greater than 90 were considered.

\section{Instrumentation Operations}

The instrument parameters for the analyses of smoke samples are shown in Table 2. The injection split and the modulation time varied for different plant species. Samples were injected into the same system with different parameters. The acquisition rates for the GC TOFMS and GCxGC TOFMS were 10 and 150 spectra/s, respectively. The split ratio varied among samples; LO, SP, and DP required a lower split ratio. The maximum modulation time was 5 seconds for each smoke sample. 
Table 2. GC-TOFMS and GCxGC-TOFMS (Pegasus BT 4D) Instrument Parameters

\begin{tabular}{|c|c|}
\hline \multicolumn{2}{|c|}{$\begin{array}{l}\text { Gas Chromatograph Agilent 7890B with LECO Dual Stage Quad jet Modulator } \\
\text { and LPAL } 3 \text { Autosampler }\end{array}$} \\
\hline Injection: & 1uL, split 20-150:1@250C \\
\hline Carrier Gas: & $\mathrm{He} @ 1.4 \mathrm{ml} / \mathrm{min}$ \\
\hline Primary Column: & $\begin{array}{l}\text { Rxi-5ms, } 30 \mathrm{~m} \times 0.25 \mathrm{~mm} \text { i.d. } \times 0.25 \mu \mathrm{m} \\
\text { coating (Restek, Bellefonte, PA, USA) }\end{array}$ \\
\hline Secondary Column: & $\begin{array}{l}\text { Rxi-17SilMS, } 0.60 \mathrm{~m} \times 0.25 \mathrm{~mm} \times 0.25 \mu \mathrm{m} \\
\text { coating (Restek, Bellefonte, PA, USA) }\end{array}$ \\
\hline Oven Programming: & $\begin{array}{l}\text { Primary column starting temperature } 50^{\circ} \mathrm{C} \text {, } \\
\text { ramped } 10^{\circ} \mathrm{C} / \mathrm{min} \text { to } 320^{\circ} \mathrm{C} \text {, hold } 5 \text { min } \\
\text { Secondary column temperature parallel } \\
\text { ramp offset by }+5^{\circ} \mathrm{C} \text { (Total run time } 32 \mathrm{~min} \text { ) }\end{array}$ \\
\hline Modulation: & $\begin{array}{l}\text { 5s with temperature maintained }+15^{\circ} \mathrm{C} \\
\text { relative to } 2 \text { nd oven }\end{array}$ \\
\hline Transfer line: & $280^{\circ} \mathrm{C}$ \\
\hline \multicolumn{2}{|c|}{ Mass Spectrometer LECO Pegasus BT 4D } \\
\hline $\begin{array}{l}\text { Ion Source } \\
\text { Temperature: }\end{array}$ & $250^{\circ} \mathrm{C}$ \\
\hline Mass Range: & $50-650 \mathrm{~m} / \mathrm{z}$ \\
\hline Acquisition Rate: & 150spectra/s (2D) or 10spectra/s (1D) \\
\hline
\end{tabular}

\section{GC and GCxGC Data Preparation}

GC/MS is one of the instrument combinations commonly used to characterize VOCs (ASTM 2018; ISO 2011). GC-TOFMS (1D) and GCxGC-TOFMS (2D) were used to characterize VOCs (DCM solvent collection) from the pyrolyzed vegetation. Characterizing some of these chemicals can be difficult because of the detectability, high volatility, and/or lack of volatility of high mass chemicals found in light tars.

To compare the methods, a diverse group of seven gas samples (1 per plant species) were collected. Due to no replication, it is not possible to identify any effect due to plant species or any interaction between species and analysis method. From each of the seven samples, four extractions were made. Two were analyzed by GC and two were analyzed by GCxGC. NIST and Wiley libraries were used to determine the similarity matches using special algorithms that find the similarities between the libraries and the samples' mass spectra. A higher similarity number indicates a better match between library and sample spectra. The number of peaks detected and the peak area percentage were summarized into four groups of compounds - hydrocarbons $(\mathrm{CH})$, oxygenated organics $(\mathrm{CHO})$, organic nonmetals (ONM), and unknown (UNK). For each sample, method, and compound group the repeat extractions were averaged for further comparisons; Figs. 3 and 4 show the extraction measurement error.

Relationships between the 1D and 2D methods for the count data initially were evaluated based on paired comparisons assuming either Poisson or negative binomial distributions, while percent area was evaluated assuming beta distributions (Table 3). A generalized linear mixed model with a fixed effect for GC method and a random effect for sample was fit using PROC GLIMMIX from SAS/STAT® V14.1 (SAS Institute Inc., Cary, NC, 2015). However, to fully understand whether the relationships between chemical group identified by the two different methods (i.e., 2D vs. 1D) shift, the data, which are compositional (i.e., constrained), were further analyzed using compositional data analysis 
(CoDA) techniques (Aitchison 1986). This adjustment for counts to relative counts also partially removes effects due to the samples having different total counts; thus, models tend to indicate the random effect for sample is not significant. It should be noted that geometric means (not accounting for sample effects) resulted in similar values as given in Table 3, but the values in Table 3 are from models that include random sample effects.

The data averaged over method and compound group were analyzed as paired samples to test for differences in the number of peaks and the peak area percentages between the two methods. Because the data were compositional, they were transformed into log-ratios using an ilr-transformation, a standard approach for compositional data (Egozcue et al. 2003). The particular ilr-transformation used, called a balance, formed scientifically meaningful log-ratios. Specifically, the log ratios of the geometric means of 1) $\mathrm{CH}$ and $\mathrm{ONM}$ vs. $\mathrm{CHO}$ and UNK, 2) $\mathrm{CH}$ vs. ONM, and 3) $\mathrm{CHO}$ vs. UNK were calculated (Egozcue and Pawlowsky-Glahn 2005). Once transformed, the data are assumed to have a normal distribution and then can be analyzed using common statistical techniques, as has been done recently with smoke emissions (Weise et al. 2020). To compare the 1D method to the $2 \mathrm{D}$ method, multivariate paired Hotelling's $\mathrm{T}^{2}$ statistic was used followed by confidence intervals on the differences (Hotelling 1931, 1951).

Observations are further made on the typical functional groups for each species. Although the species were not replicated for this study, the groupings from GCxGC are important to understand their reliability in the context of other research in the literature. Details and discussion are provided that further explain GCxGC plots and visually trending data relative to the wildfire smoke's typical functional groupings for the two species Live Oak and Longleaf Pine. Molecular chemical maps (MCM) are developed and explained to aid groupings. Understanding how these MCMs are developed will aid in understanding the statistical summaries of the data when more samples can be evaluated.

\section{RESULTS AND DISCUSSION}

\section{One-Dimensional versus Two-Dimensional Gas Chromatography}

Table 3 shows a wide range in the number of peaks identified by the two methods. Due in part to the small sample size and diversity of samples, the sizes of the 95 percent confidence intervals were quite large. The multivariate paired Hotelling $\mathrm{T}^{2}$ test indicated that the composition of the white smoke as described by the relative number of peaks in the four chemical groups differed significantly between the GC methods (Prob $>F_{3,4}=$ 0.00004). In contrast, the relative peak area percentages in the four chemical groups did not differ between the GC methods (Prob $>\mathrm{F}_{3,4}=0.1258$ ).

The difference plots with 95\% Bonferroni confidence intervals (Fig. 2) can be used to determine where the estimated effect of GC method on the particular balances occurred. Recall only the number of peaks was significantly affected by the GC analysis method across the balances. In Fig. 2a, the 95\% confidence intervals for the log-ratio of the $\mathrm{CH}$ compounds to ONM and the log-ratio of the sum of $\mathrm{CH}$ and ONM to the sum of $\mathrm{CHO}$ and UNK both narrowly include zero. It appears that the differences based on these two balances were correlated, which could be impacting the overall vs. individual tests. The average difference greater than 0 indicates that relatively more peaks were observed in the $\mathrm{CH}$ compared to ONM in the 1D method as opposed to the 2D method. 
Table 3. Summary Statistics for two GC Methods Used to Determine Chemical Composition of "White Smoke" Samples Collected from Live Fuel Samples in a Cone Calorimeter. Estimated Means, Standard Errors and 95\% Confidence Intervals are Given

\begin{tabular}{|c|c|c|c|c|c|}
\hline \multirow{2}{*}{ Method } & \multicolumn{4}{|c|}{ Number of Peaks } & \multirow[b]{2}{*}{ Total $^{c}$} \\
\hline & $\mathrm{CH}^{\mathrm{ab}}$ & $\mathrm{CHO}^{\mathrm{b}}$ & $\mathrm{UNK}^{\mathrm{c}}$ & $\mathrm{ONM}^{\mathrm{C}}$ & \\
\hline \multirow[t]{2}{*}{ GC } & $25(4.2)^{*}$ & $170(25.6)^{*+}$ & $265(57.9)^{\star}$ & $80(12.2)^{*+}$ & $546(96)^{\star+}$ \\
\hline & $(17,38)$ & $(118,246)$ & $(155,452)$ & $(56,117)$ & $(355,838)$ \\
\hline \multirow[t]{2}{*}{ GCxGC } & $38(6.1)$ & $286(42.8)$ & 481(104.8) & $267(39.0)$ & 1074(188) \\
\hline & $(26,56)$ & $(198,412)$ & $(282,819)$ & $(187,382)$ & $(701,1648)$ \\
\hline \multirow[t]{2}{*}{ Method } & \multicolumn{4}{|c|}{ Relative Number of Peaks } & \\
\hline & $\mathrm{CH}^{\mathrm{d}}$ & $\mathrm{CHO}^{\mathrm{d}}$ & $\mathrm{UNK}^{\mathrm{d}}$ & $\mathrm{ONM}^{\mathrm{d}}$ & Total \\
\hline \multirow[t]{2}{*}{ GC } & $4.8(0.68)$ & $32.8(2.25)$ & $47.6(2.66)$ & $14.6(0.64)^{*+}$ & 100 \\
\hline & $(3.4,6.8)$ & $(27.5,38.5)$ & $(41.2,54.1)$ & $(13.1,16.2)$ & \\
\hline \multirow[t]{2}{*}{ GCxGC } & $3.6(0.54)$ & $26.6(2.12)$ & $44.6(2.65)$ & $25.0(0.92)$ & 100 \\
\hline & $(2.5,5.2)$ & $(21.8,32.1)$ & $(38.3,51.2)$ & $(22.8,27.4)$ & \\
\hline \multirow[t]{2}{*}{ Method } & \multicolumn{4}{|c|}{ Peak Area Percentage } & \\
\hline & $\mathrm{CH}^{\mathrm{d}}$ & $\mathrm{CHO}^{\mathrm{d}}$ & $\mathrm{UNK}^{\mathrm{d}}$ & ONM $^{d}$ & Total \\
\hline \multirow[t]{2}{*}{ GC } & $0.64(0.09)$ & $44.60(5.16)$ & 40.96(6.09) & $12.95(4.06)^{*}$ & 100 \\
\hline & $(0.45,0.91)$ & $(32.56,57.30)$ & $(27.24,56.24)$ & $(5.80,26.42)$ & \\
\hline \multirow[t]{2}{*}{ GCxGC } & $0.83(0.10)$ & $32.93(4.88)$ & $31.62(5.76)$ & $34.04(6.83)$ & 100 \\
\hline & $(0.61,1.12)$ & $(22.24,45.74)$ & $(19.41,47.02)$ & $\begin{array}{l}(19.69, \\
52.06)\end{array}$ & \\
\hline
\end{tabular}

a. $\mathrm{CH}$ - hydrocarbons, $\mathrm{CHO}$ - oxygenated organics, UNK - unknown, ONM - organic non-metals

b. Poisson distribution assumed.

c. Negative binomial distribution assumed.

d. Beta distribution assumed.

*individual test $p$-value $<0.05$, not adjusted for multiple comparisons or dependencies

+Bonferroni adjusted $p$-value $<0.0038(0.05 / 13)$ 
The log-ratio of CHO to UNK is closer to 0 , suggesting that their proportions were not impacted by GC method. While the $95 \%$ Bonferroni intervals for peak area differences (Fig. 2b) indicate a difference between GC method for the log-ratio of the sums, the overall Hotelling $\mathrm{T}^{2}$ indicated that the collection of log-ratios were not significant at the 0.05 level.

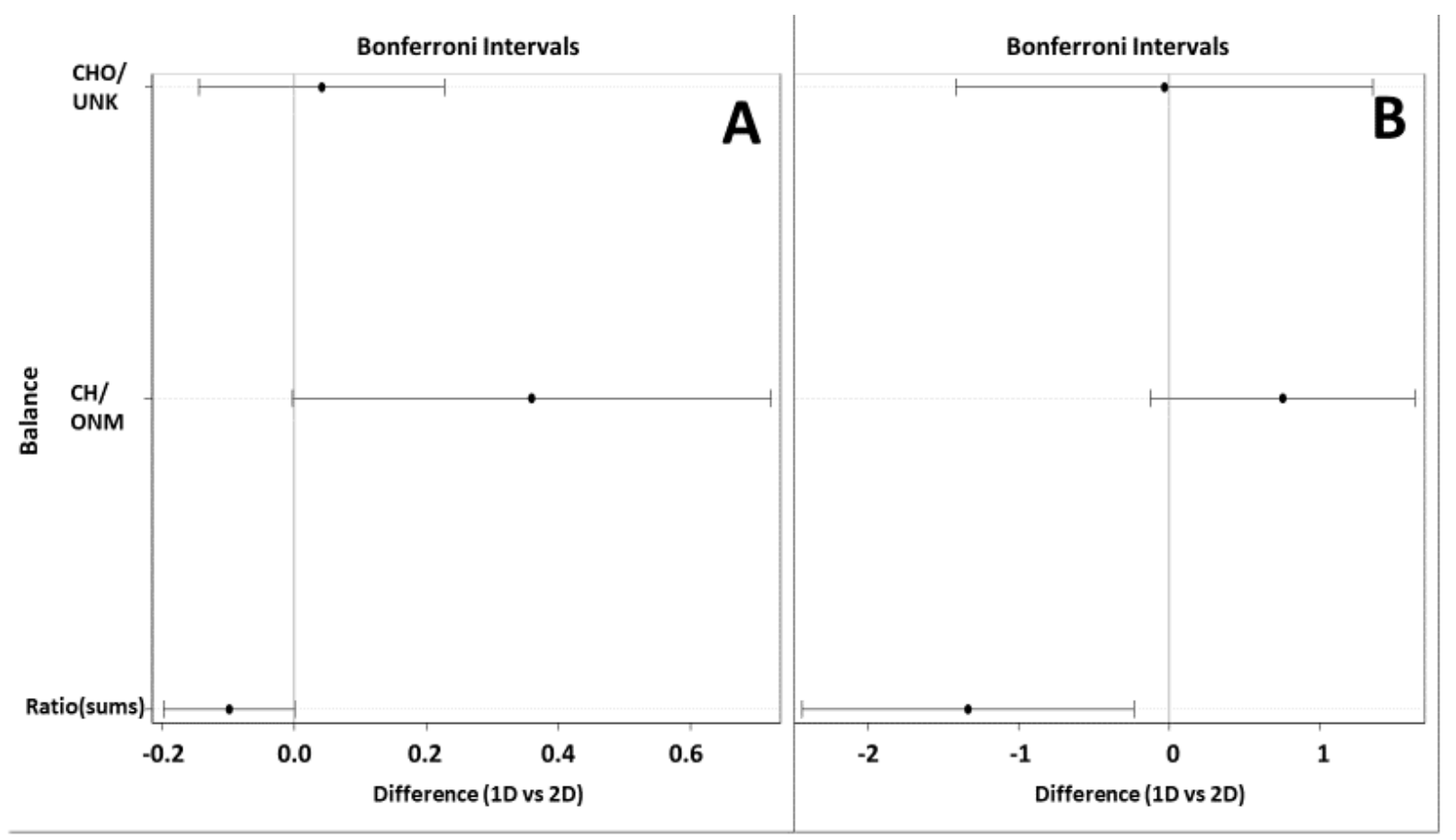

Fig. 2. Influence of GC analysis method on selected balances of chemical groupings. Values plotted are the average difference of log-ratios between 1D versus 2D for the indicated balance with 95\% Bonferroni interval for that balance: (a) relative number of peaks, (b) area of peaks. Average difference less than 0 indicates either relatively less in the numerator or relatively more in the denominator of the balance.

It is important to remember that these data are relative and not absolute values. In summary, these limited data tend to suggest that the 1D GC analysis method yielded a relatively larger number of peaks in the $\mathrm{CH}$ category compared to the ONM category, or equivalently that the 2D GC analysis method yielded a relatively larger number of peaks in the ONM category compared to the $\mathrm{CH}$ category and that the log-ratio of sums of the chemical groups may be impacted as well.

Figures 3 and 4 show the raw data and suggest that there was a significant difference between 1D and 2D GC methods for the number of chemicals. The increase in diversity of chemicals will assist with the NMOC aerosols chemical gap, as discussed in the literature (Yokelson et al. 2013). The maximizing of tar production was achieved in the cone calorimeter under irradiance of $35 \mathrm{kWm}^{-2}$ at a final temperature range of 400 to $600{ }^{\circ} \mathrm{C}$ along with the full smoldering in air to nearly zero ash. These conditions provided a severe smoke profile containing primary pyrolysis products. These organic tars were separated into various categories and characterized in the $2 \mathrm{D}$ analysis.

The observance of nil ash weight after the tests was confirmed by the high number of ONM compounds. The observance of white smoke penetrating through the filters into the DCM solution seemed sufficiently rapid for avoiding the condensation reactions that form creosote in alternate smoke sampling schemes. 


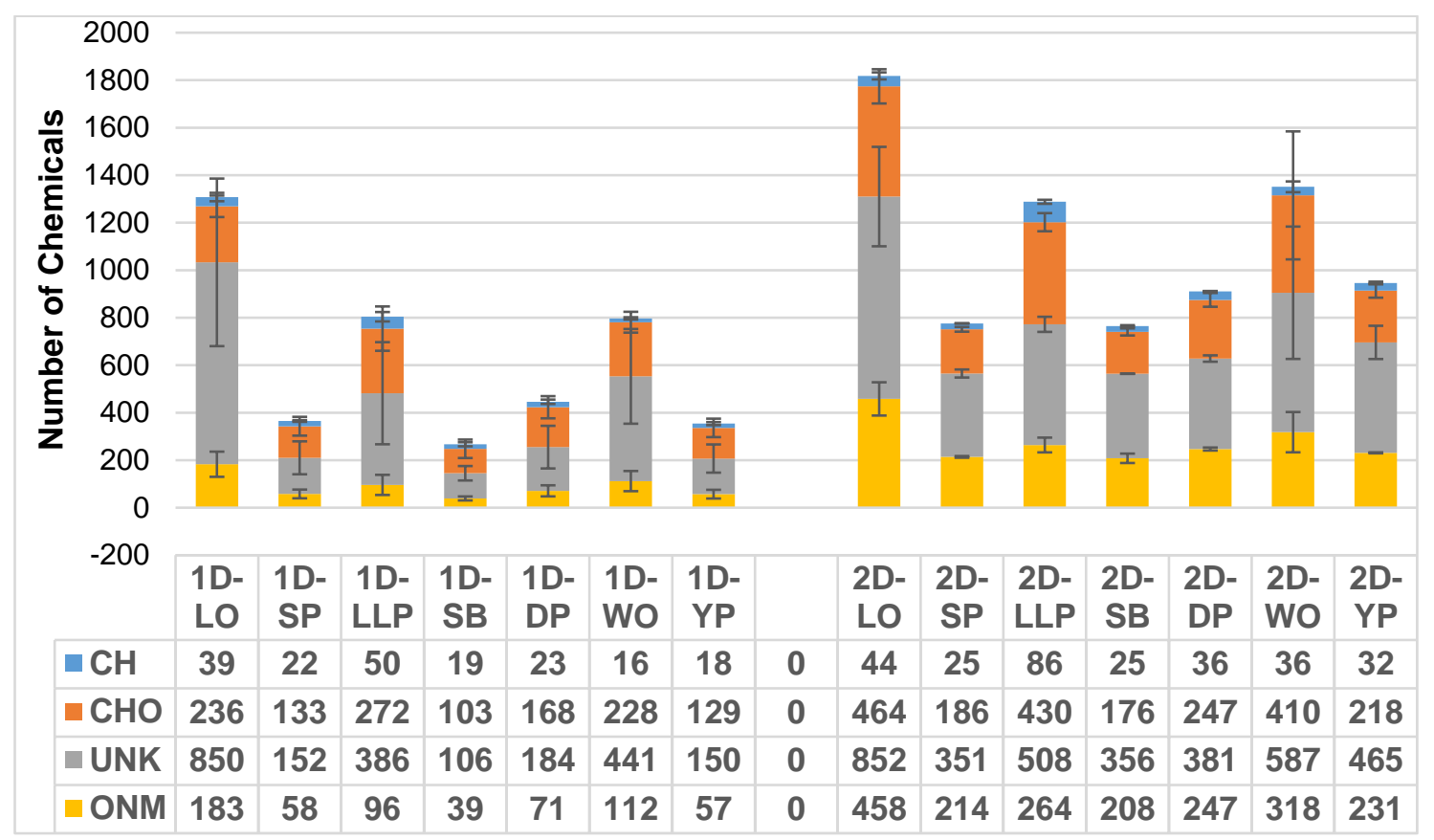

Fig. 3. $1 \mathrm{D}$ and $2 \mathrm{D}$ analysis of the number of peaks separated in DCM solution collected from seven vegetation pyrolysis white smoke tests. Chemicals are grouped by hydrocarbons $(\mathrm{CH})$, oxygenated organics (CHO), unknowns (UNK), and organic non-metals (ONM) for the seven samples.

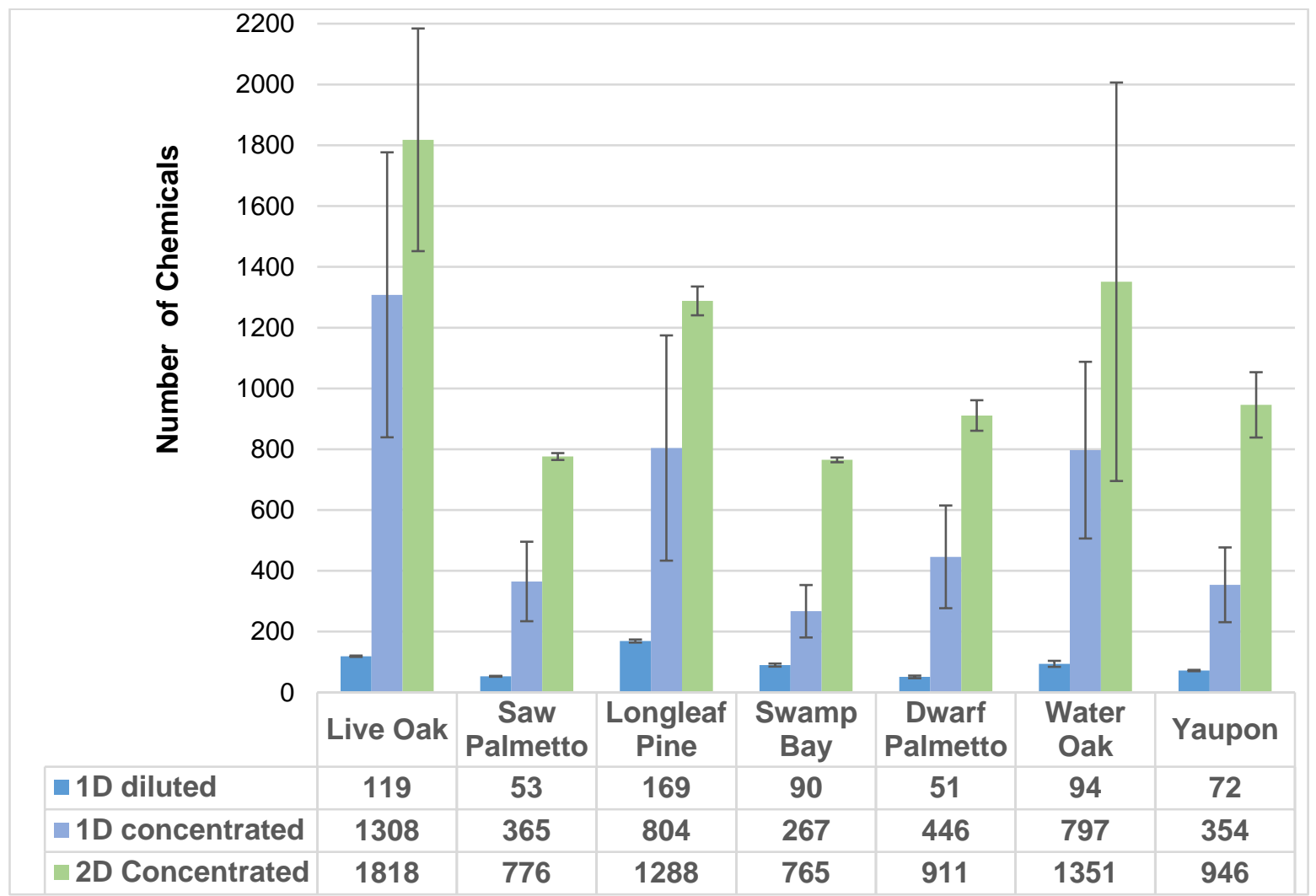

Fig. 4. The number of chemicals detected in DCM solution utilizing GC-TOFMS compared with GCxGC-TOFMS 
Although the white smoke collected does deviate from other smoke sampling schemes, the overall purpose was to increase number of pyrolysis products likely to be produced in the field and to aid the goals of the project for numerical pyrolysis modelling.

\section{Categorizing GCxGC Oxygenated Organics by Functional Groups}

Figures 5 and 6 are refined separations of the raw data from $\mathrm{CH}$ and $\mathrm{CHO}$ categories for each sample. The endings of the chemical names were used to group items together to classify the chemical categories. Functional group (FG) classifications were -one (ketones), -ol (alcohols), -ane (alkanes), -ene (alkenes), -yne (alkynes), -ose (sugars), -al (aldehyde), and PAH, esters, acids, ide, furans, and miscellaneous (misc). Figure 5 and 6 show the number of chemicals and the peak area (PA\%) of the FG classifications for the samples.

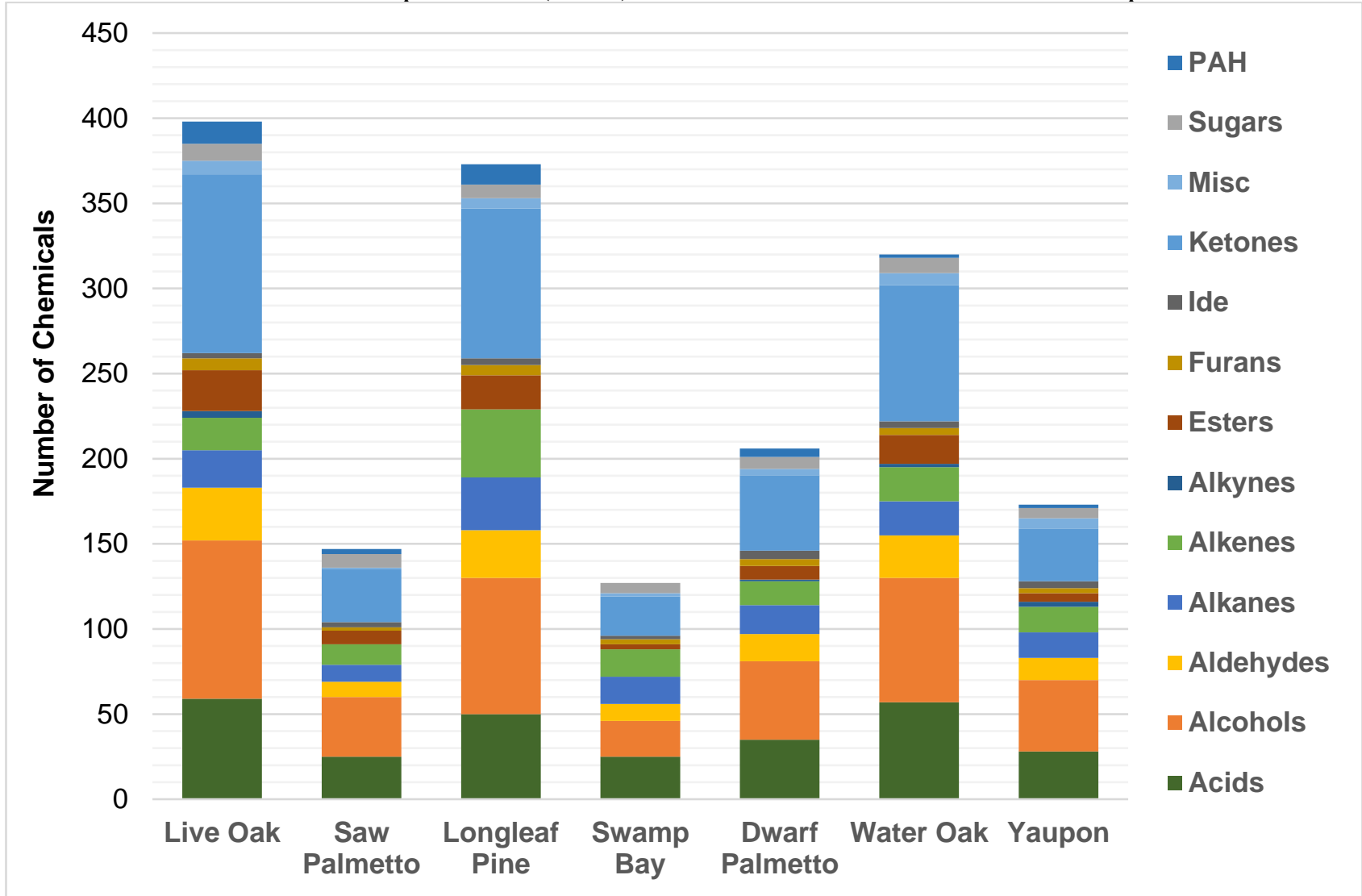

Fig. 5. The number of chemicals identified and their functional groups types for each vegetation sample from the pyrolysis analyses

LO, LLP, and WO were the vegetation with the greatest number of chemicals from $\mathrm{CH}$ and $\mathrm{CHO}$, as shown in Fig. 5. The classes of chemicals identified with the most diversity were ketones, alcohols, and acids. The number of chemicals identified as PAHs were not numerous. This is to be expected because aromatization occurs at higher temperatures (Zhao et al. 2017; Sekimoto et al. 2018). Methoxy and phenolic hydroxyl were the major chemical groups found in lignin and (poly)phenolic compounds. The phenolic chemicals were grouped with alcohols, which could be a strong component of alcohols being one of the most abundant chemicals identified. The alkanes and alkenes classification included aromatic compounds. This is consistent with the literature (Amini et al. 2019). Tar from the pyrolysis of similar vegetations was composed mostly of ketones, alcohols, and acids. The number of such chemicals appear to be significant. 


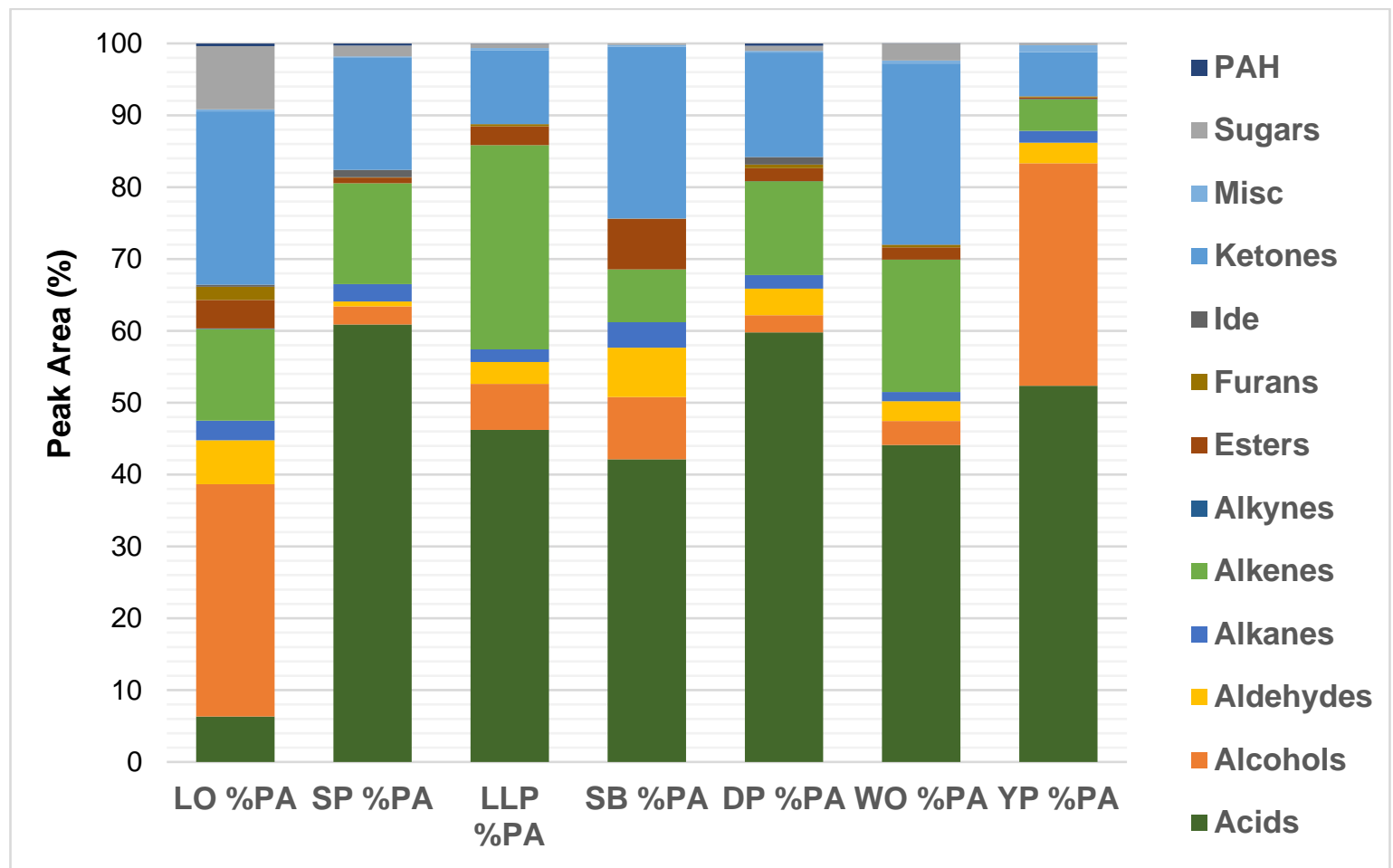

Fig. 6. Functional groups $\mathrm{PA} \%$ in each vegetation sample

Figure 6 shows the PA\% comparison for the seven plant samples. Within each vegetation, the PA\% showed that there were major differences between the alcohols, ketones, and acids. Acids were the most abundant in six of the vegetations. SP, DP, and YP had the highest acid PA\%, which was 61, 60, and 52\%, respectively. LO, SB, and WO had the most abundant ketones at 24, 24, and 25 PA\%, respectively. The $44 \%$ of acids reported in the literature was for carboxylic acids (Wang et al. 2017). The alkenes in LLP stood out among the vegetation at $24 \%$. The contributing chemicals to this increase were aromatic compounds, and as reported later in the paper, there were several benzene compounds identified in this group. During pyrolysis, benzene rings were a major contributor to the formation of PAHs at higher temperatures. Another interesting observation was that there were three vegetation samples that had no alkynes detected. These were SP, LLP, and SB. This is especially noteworthy because alkynes are known to be a part of the chemical makeup of LLP extractives. During pyrolysis, many chemicals were degraded to form other chemicals. Alkynes are triple-bonded carbons; this bond structure is very unstable during pyrolysis. Benzene and alkynes were a part of a mechanism to form PAHs (Norinaga et al. 2014). The absence of alkynes and the abundance of alkenes (benzene) could contribute to the formation of PAHs. The 2D analysis provided a qualitative perspective, which can assist with characterizing the chemicals in the vegetation samples. The chromatograms produced from the data create a visual image of the locations of the unidentified and identified chemicals.

\section{GCxGC Plots and Trending Data}

GCxGC chromatograms are a three-dimensional view of the samples. Figure 7 contains different chromatogram styles for viewing the injected samples. The top is the surface plot, and the bottom is the contour plot with the 1D chromatogram to the left. The surface plot shows the $1^{\text {st }}$ and $2^{\text {nd }}$ retention times and the intensity of the peaks. Red 
represents the most intense peak for the different chemicals. The surface plot also gives a better view of coeluting chemicals. The ripples in the blue surface are trace chemicals that have been detected. From the contour view, any coeluting chemicals and any chemicals that would be hiding because of concentration can be seen. Yellow and red represent the intensity. Red is the most concentrated, and yellow is the least. The black dots are trace chemicals that have been either identified or detected. The 1D chromatogram shows high concentrated and coeluting peaks, making it difficult to identify (Dimandja et al. 2000; Dimandja 2004). These characteristics are what sets the $2 \mathrm{D}$ analysis apart from the $1 \mathrm{D}$ analysis.

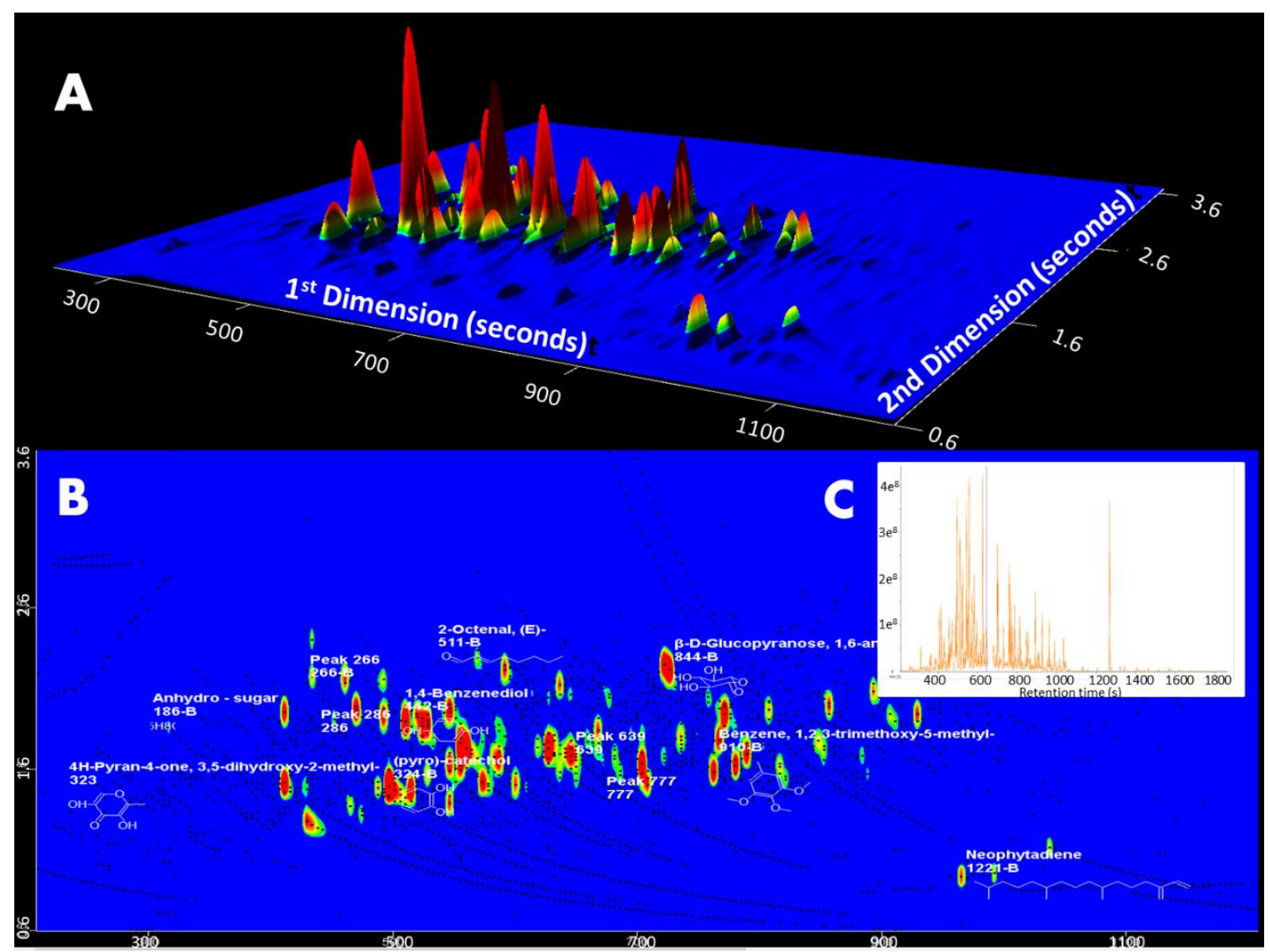

Fig. 7. Live Oak GCxGC (A) surface, (B) contour and one-dimensional GC (C) chromatograms

One-dimensional analysis has been used to model and predict 2D comprehensive retention times (Dimandja 2003; Seeley and Seeley 2007). From the GCxGC chromatogram data, MCM were created to visually locate the classified FGs. Figures 8 through 11 are the plots of the chemicals identified and labeled with a color to represent different FGs. These colors will assist in identifying the FG trends.

Figure 8 contains plots of the $\mathrm{CH}$ and $\mathrm{CHO}$ categories colorized by their FG for LO and LLP. The FG are colorized to identify retention trends for FG classifications. Cross sections were created using a y-axis retention time of 2.5 seconds and an $\mathrm{x}$-axis retention time of 1000 seconds. In both plots, four quadrants (Q1-Q4) were established and will be used in Figs. 8 through 11. There was clustering of FG chemicals in Q1 for both plots. However, LO is denser with chemicals than LLP in Q1. As the retention time increased, the chemicals eluted into a gradual line appearing to travel up from Q4 to Q3 in the LLP. 
LO gradually expanded into Q4 but not into Q3. There were various FG chemicals gathering between 1400 and 2000 seconds at the bottom in Q4 for LO and LLP. An MCM was used to identify visual trends for different chemical FGs. (Moore and Mann 2020a, 2020b, 2020c; Moore et al. 2020). The increase of retention time on the $\mathrm{x}$-axis is attributable to chemicals with higher molecular weight and least volatility. On the y-axis, which is the $2^{\text {nd }}$ dimension retention time (semipolar column), the chemicals retained on the column the longest were more polar. The chemicals tailing from Q4 to Q3 on LLP (black arrows) were an indication that chemicals were polar and high in molecular weight (Dimandja et al. 2003a). The light blue and red arrows represent trending alkanes, acids, and alcohols in both vegetations. These trends are in Q2 and Q4. The LLP trending alkanes eluted early in Q2, and LO trending alkanes eluted later in Q4 during the analysis.
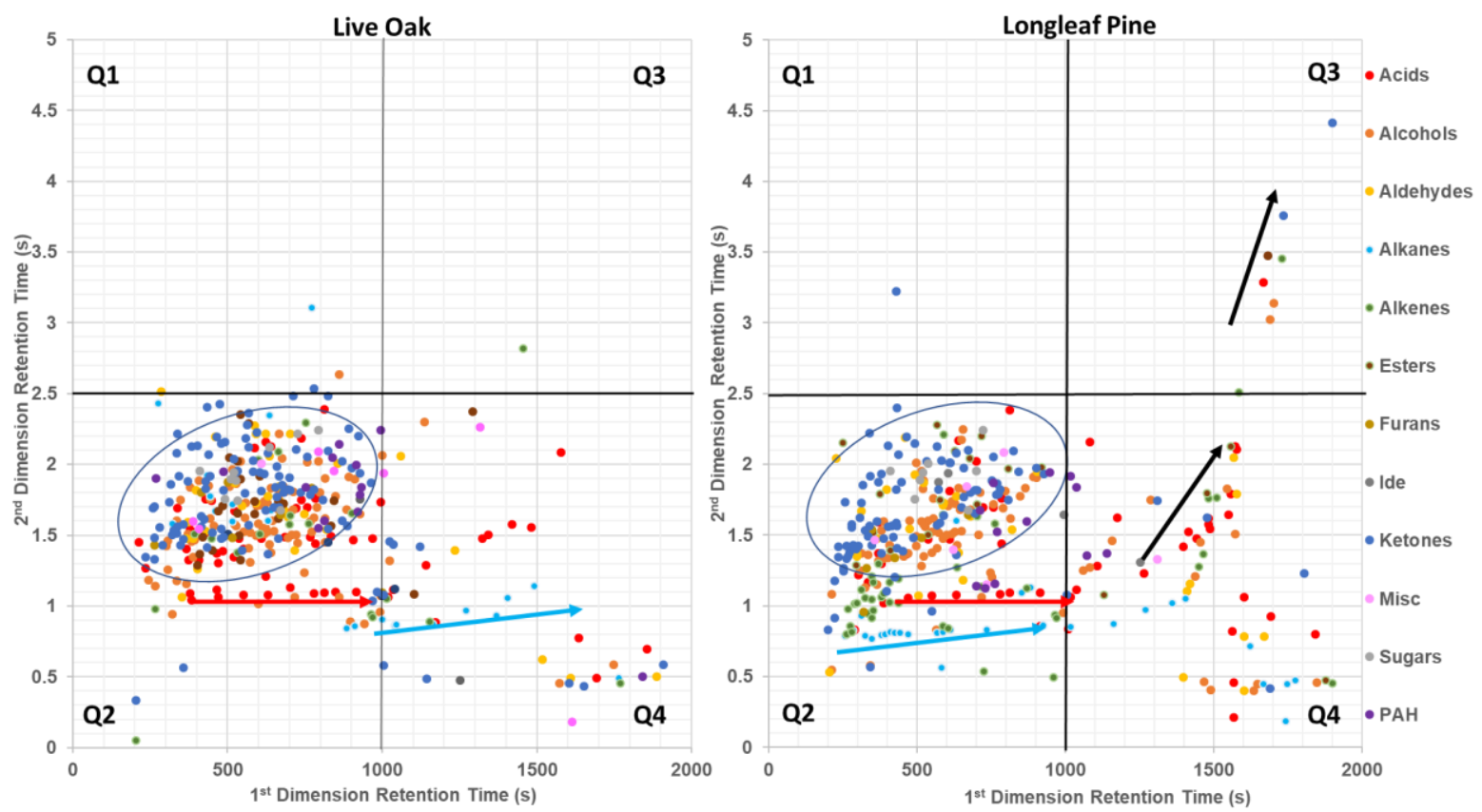

Fig. 8. MCMs of the functional groups of the pyrolysis LO and LLP samples
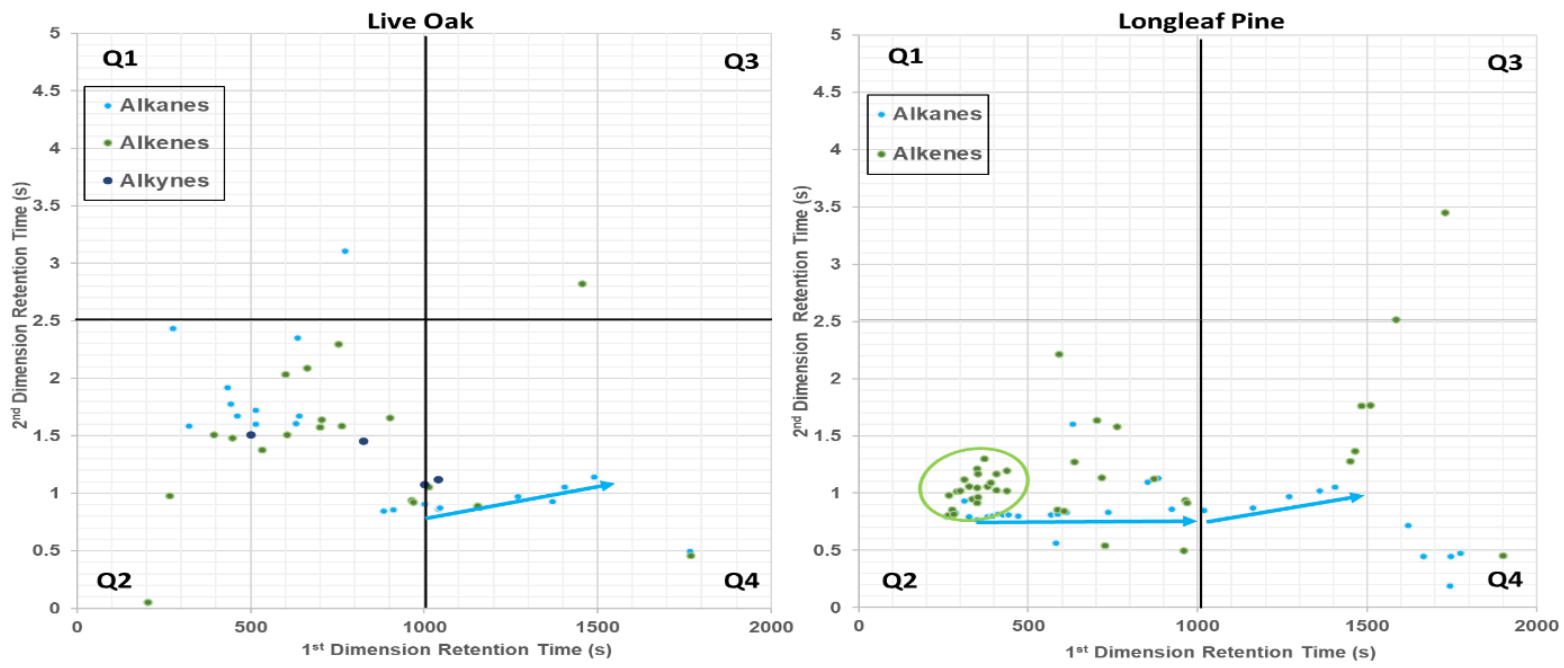

Fig. 9. MCMs of the alkanes, alkenes, and alkynes in the pyrolysis LO and LLP samples. Light blue: trend of saturated alkanes, Green circle: (PAH intermediates) 
Figure 9 shows LO and LLP MCMs of FG alkanes, alkenes, and alkynes. There were no alkynes identified in LLP, but there were four detected in LO. There was no notable trend for alkynes in the MCM plot for LO. The types of chemicals in the FG classification were short hydrocarbon chains, long hydrocarbon chains, and aromatic organic chemicals.

The hydrocarbon chain of FG alkanes was slightly below 1 second on the $2^{\text {nd }}$ dimension for both plots. The retention times for hydrocarbons eluted in Q2 and Q4 for both vegetations. There were more hydrocarbon alkanes in the LLP MCM plot. Long or short chain alkanes elute based on their volatility on the $1^{\text {st }}$ dimension axis (Seeley and Seeley 2007). The longer the chain, the longer the retention time. There were some alkene hydrocarbon chains, but there was no notable trend. In Q2 chemicals with their base name benzene clustered together. A green circle was placed around the clustering of benzene chemicals in Fig. 10.

As the retention time increased, the chain length of the hydrocarbons and the molecular weight increased. The alkanes on the LLP MCM plot had low molecular weight, starting the trend. As the retention time increased the molecular weight increased (Moore and Mann 2020a,b,c; Moore et al. 2020).
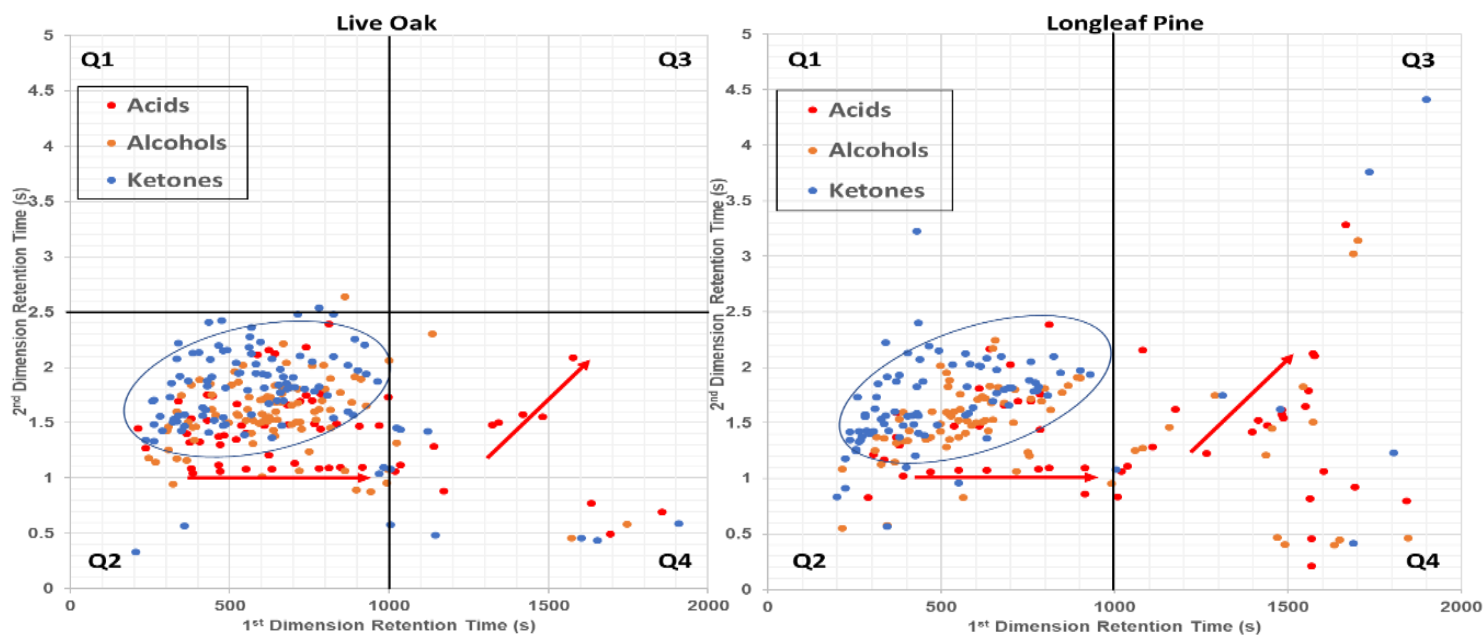

Fig. 10. MCMs of the ketones, alcohols and acids in the seven pyrolysis LO and LLP samples. Red arrow: trend of fatty acids

Alcohol, ketone, and acid FGs had the greatest diversity of chemicals across the white smoke of seven vegetations. Figure 10 shows the positions of the chemicals of these FGs. Most of the clustered chemicals noted in Fig. 10 were comprised of alcohol, ketone, and acid FGs. A cluster of chemicals on the MCM can make it difficult to identify a visual trend. Aromatic trends are difficult to identified in the 2D analysis. However, one trend identified in the alkane FG was the formation of hydrocarbon chain chemicals eluting based on volatility. This trend held true for fatty alcohols and acids. They eluted slightly above 1 second on the $2^{\text {nd }}$ dimension (y-axis). In Q3, LO had no chemicals to elute, but in the LLP plot there were four higher molecular weight chemicals. This area elutes polar chemicals with higher molecular weights. Q3 is not limited to acids, alcohols, and ketones. Esters and aldehydes also eluted in Q3, but the esters and aldehydes were not shown. The classification of chemicals that eluted in Q4 were lipid sterols (Dimandja et al. 2000). These chemicals are classified in the ketone and alcohol FGs. 
Visual trends on the MCM are important to identifying the unknowns in the vegetation samples (Moore and Mann 2020a,b,c; Moore et al. 2020). There were many unknowns detected in each sample. Establishing quadrants will assist with locating known trends. These neighboring chemicals can assist with identifying the unidentified chemicals.

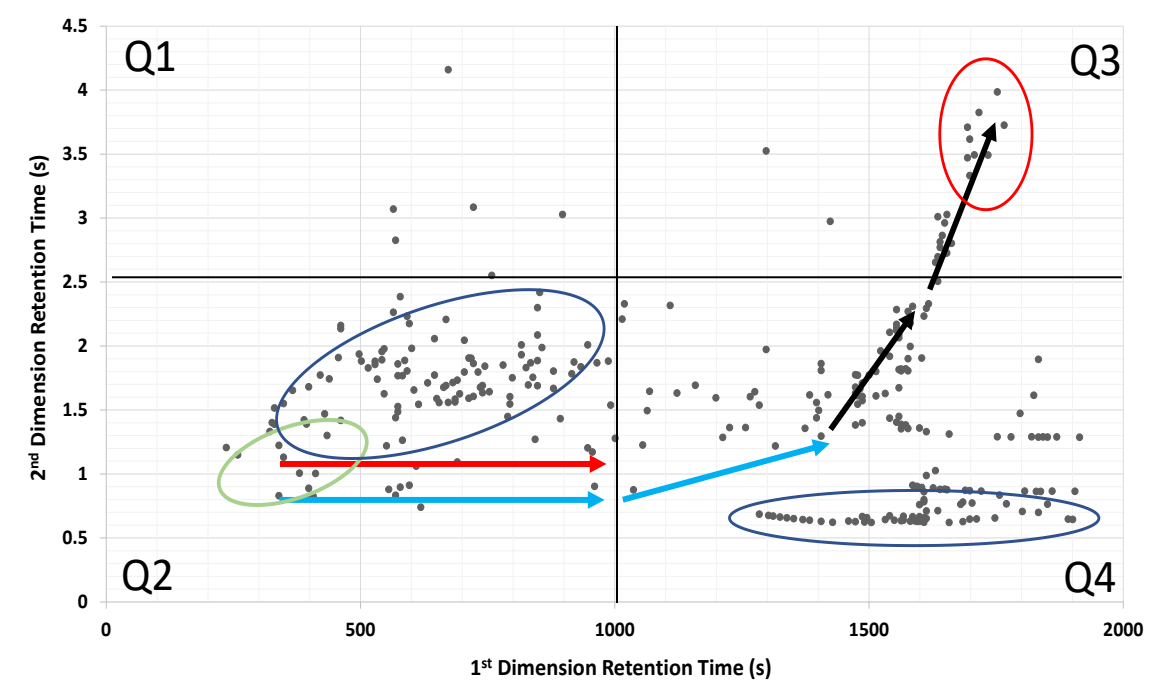

Fig. 11. LLP MCM of unidentified chemicals detected in the LLP smoke mixture. Red circle: sterols, Blue circle: alcohols, ketone, acids, Red arrow: trend of fatty acids, light blue: trend of saturated alkanes

The LLP MCM of the unidentified peaks was created (Fig. 11) and labeled with the arrows and circles to represents the trends of the chemicals in the FG classification (Moore and Mann 2020a,b,c; Moore et al. 2020). The red arrow represents the location of the fatty acids and alcohols identified from the known LLP MCM. The light blue arrow represents the short and long chains of alkanes. The green circle is the location where the PAH intermediates and, aromatics chemicals eluted. The blue circle in Q2 is where the majority of the alcohol, ketone, and acid FGs eluted. The black arrows from Q4 to Q3 point out high mass fatty acids and alcohols. The red circle in Q3 is where the lipid sterols eluted. The data showed that the phenols formed a line trend at 1.5 seconds on the $2^{\text {nd }}$ dimension. These trends will prove to be useful with interpreting the spectra with unknown chemicals (Dimandja et al. 2000, 2003a,b). Q4 on the $1^{\text {st }}$ dimension 1200 to 2000 seconds and between 0.5 to 1 on the $2^{\text {nd }}$ dimension are typically column bleed, but with further investigation, other trends might be established.

\section{CONCLUSIONS}

1. Two-dimensional gas chromatography time of flight mass spectrometry (GCxGC TOFMS) appears to give more information than the one-dimensional method (GC 1D) for the number of compounds identified and a difference between the ratios of hydrocarbon $(\mathrm{CH})$ to organic non-metals $(\mathrm{ONM})$ categories.

2. The peak area percent (PA\%) between samples for the 1D and 2D GC method were not statistically different, but their differences based on designated balances tended to be similar in direction as those based on relative counts. 
3. Statistics were based on relative and not absolute values due to the compositional nature of the data, heterogeneity of sample types, and to better understand how the two methods differ on recognizing important function groups.

4. Ketones, acids, and alcohols appeared to be the most abundant and diverse number of chemicals among the $\mathrm{CH}$ and $\mathrm{CHO}$ categories.

5. Acids appeared to be the highest PA\% among the $\mathrm{CH}$ and $\mathrm{CHO}$ categories.

6. Molecular chemical maps (MCM) were used to visually identify chemical trends in known and unknown chemicals in live oak (LO) and longleaf pine (LLP).

7. Hatch et al. (2015) were among the first to utilize GCxGC to investigate non-methane organic compounds (NMOC). This work is significant to model when characterizing aerosols, even though our collection method, GCxGC parameter, and the ignition for samples used a cone calorimeter.

8. In conclusion, future work will include identifying similar chemicals in the various samples for fire modeling, calculating more data points, and identifying trends and unknown chemicals using the MCM.

\section{ACKNOWLEDGEMENTS}

This work was partially supported by DOD/EPA/DOE Strategic Environmental Research and Develop Program Project RC-2640 administered by the USDA Forest Service, PSW Research Station. The authors thank the staff of FPL for their support of this work and Maija Lee and Alfred Sunaryo for the processing the GCxGC raw data.

The use of trade or firm names in this publication is for reader information and does not imply endorsement by the U.S. Department of Agriculture of any product or service.

\section{REFERENCES CITED}

Aitchison, J. (1986). The Statistical Analysis of Compositional Data, Monographs on Statistics and Applied Probability, Chapman and Hall, London.

Amini, E., Safdaria, M. S., DeYounga, J., Weise, D., and Fletchera, T. (2019). "Characterization of pyrolysis products from slow pyrolysis of live and dead vegetation native to the southern United States," Fuel 235, 1475-1491. DOI: 10.1016/j.fuel.2018.08.112

ASTM D6420-18. (2018). "Standard test method for determination of gaseous organic compounds by direct interface gas chromatography-mass spectrometry," ASTM International, West Conshohocken, USA.

Barboni, T., Leonelli, L., Santoni, P.-A., and Tihay-Felicelli, V. (2020). "Aerosols and carbonaceous and nitrogenous compounds emitted during the combustion of dead shrubs according to twigs' diameter and combustion phases," Fire Safety Journal 113, 102988. DOI: 10.1016/j.firesaf.2020.102988

Biology Libretexts (2020). "30.4C: Leaf Structure, function, and adaption," (https://bio.libretexts.org/Bookshelves/Introductory_and_General_Biology/Book\%3A _General_Biology_(Boundless)/30\%3A_Plant_Form_and_Physiology/30.4\%3A_Lea 
ves/30.4C\%3A_Leaf_Structure_Function_and_Adaptation), Accessed 10 December 2020.

Bordiga, M., Coisson, J. D., Travaglia, F., Piana, G., and Arlorio, M. (2009). "HSSPME/GCxGC/ TOF-MS: A powerful tool for off-flavors identification in Italian muscat-based wines," CZECH Journal of Food Science 27, S227-S227.

Butry, D., Mercer, E., Prestemon, J., Pye, J., and Holmes, T. (2001). "What is the price of catastrophic wildfire?," Journal of Forestry 99(11), 9-17.

Bytnerowicz, A., Arbaugh, M. A., Andersen, C. K., and Riebau, A. R. (eds.) (2009). Wildland Fires and Air Pollution, Developments in Environmental Science, Elsevier, Amsterdam.

Dietenberger, M., Boardman, C., Shotorban, B., Mell, W., and Weise, D. (2020). "Thermal degradation modeling of live vegetation for fire dynamic simulator," in: 2020 Spring Technical Meeting Central States Section of The Combustion Institute, Huntsville, AL, USA.

Dimandja, J.-M. D., Stanfill, S. B., Grainger, J., and Patterson, Jr., D. G. (2000). "Application of comprehensive two-dimensional gas chromatography (GCXGC) to the qualitative of essential oils," Journal of High Resolution Chromatography 23(3), 208-214. DOI: 10.1002/(SICI)1521-4168(20000301)23:3<208::AIDJHRC208>3.0.CO;2-I

Dimandja, J.-M. D. (2003a). "Prediction of GCXGC separation through the use of retention index data," In: 99th Gulf Coast Conference, Galveston Island, TX, USA. Abstract \#110.

Dimandja, J.-M. D., Clouden, G. C., Colón, I., Focant, J. F., Cabey, W. V., and Parry, R. C. (2003b). "Standardized test mixture for the characterization of comprehensive twodimensional gas chromatography columns: The Phillips mix," Journal of Chromatography A. 1019, 261-272. DOI: 10.1016/ j.chroma.2003.09.027

Dimandja, J.-M. D. (2004). “Comprehensive 2 D GC provides high performance separations in terms of selectivity, speed, and structure," Analytical Chemistry 76(9), 167A-174A.

Egozcue, J. J., Pawlowsky-Glahn, V., Mateu-Figueras, G., and Barceló-Vidal, C. (2003). "Isometric logratio transformations for compositional data analysis," Mathematical Geology 35, 279-300. DOI: 10.1023/A:1023818214614

Fletcher, T., Pickett, B., Smith, S., Spittle, G., Woodhouse, M., Haake, E., and Weise, D. R. (2007). "Effects of moisture on ignition behavior of moist California chaparral and Utah leaves," Combustion Science and Technology 179(6), 1183-1203. DOI: 10.1080/00102200601015574

Green, L. R. (1981). Burning by Prescription in Chaparral (General Technical Report No. PSW-51), USDA Forest Service, Pacific Southwest Forest and Range Experiment Station, Berkeley, CA.

Groenewold, G. S., Johnson, K. M., Fox, S. C., Rae, C., Zarzana, C. A., Kersten, B. R., Rowe, S. M., Westover, T. L., Gresham, G. L., Emerson, R. M., and Hoover, A. N. (2017). "Pyrolysis two-dimensional GC-MS of Miscanthus biomass: Quantitative measurement using an internal standard method," Energy Fuels 31, 1620-1630. DOI: 10.1021/acs.energyfuels.6b02645

Hotelling, H. (1931). "The generalization of Student's ratio," The Annals of Mathematical Statistics, Institute of Mathematical Statistics 2(3), 360-378. 
Hotelling, H. (1951). "A generalized T test and measure of multivariate dispersion," in: Proceedings of the Second Berkeley Symposium on Mathematical Statistics and Probability, Berkeley, CA, USA.

ISO 16000-6:2011 (2011). "Indoor air — Part 6: Determination of volatile organic compounds in indoor and test chamber air by active sampling on Tenax TA sorbent, thermal desorption and gas chromatography using MS or MS-FID," International Organization for Standardization, Geneva, Switzerland.

Hatch, L., Luo, W., Pankow, J., Yokelson, R., Stockwell, C., and Barsanti, K. (2015). "Identification and quantification of gaseous organic compounds emitted from biomass burning using two-dimensional gas chromatography-time-of-flight mass spectrometry," Atmospheric Chemistry and Physics 15, 1865-1899. DOI: 10.5194/acp-15-1865-2015

Jen, C., Hatch, L., Selimovic, V., Yokelson, R., Weber, R., Fernandez, A., Kreisberg, N., Barsanti, K., and Goldstein, A. (2019). "Speciated and total emission factors of particulate organics from burning western US wildland fuels and their dependence on combustion efficiency," Atmospheric Chemistry and Physics 19, 1013-1026. DOI: 10.5194/acp-19-1013-2019

Knorr, A., Almstetter, M., Martin, E., Castellon, A., and Pospisil, P., and Bentley, M. (2019). "Performance evaluation of a nontargeted platform using two- dimensional gas chromatography time-of-flight mass spectrometry integrating computer-assisted structure identification and automated semiquantification for the comprehensive chemical characterization of a complex matrix," Analytical Chemistry 91, 9129-9137. DOI: 10.1021/acs.analchem.9b01659

Kohl, A., Cochran, J., and Cropek, D. (2010). "Characterization of military fog oil by comprehensive two-dimensional gas chromatography," Journal of Chromatography A. 1217(4), 550-557. DOI: 10.1016/j.chroma.2009.11.054

Kukhar, I., Orlovskiy, S., and Martynovsakaya, S. (2020). "Forest fires environmental impact study," in: IOP Conference Series: Earth and Environmental Science 2020 548(5), 052061. DOI: 10.1088/1755-1315/548/5/052061

Leonellia, L., Barboni, T., Santoni, P. -A., Quilichini, Y., and Coppalle, A. (2017). "Characterization of aerosols emissions from the combustion of dead shrub twigs and leaves using a cone calorimeter," Fire Safety Journal 91, 800-810. DOI: 10.1016/j.firesaf.2017.03.048

Li, H., Lamb, K. D., Schwarz, J. P., Selimovic, V., Yokelson, R. J., McMeeking, G. R., and May, A. A. (2019). "Inter-comparison of black carbon measurement methods for simulated open biomass burning emissions," Atmospheric Environment 206, 156-169. DOI: 10.1016/j.atmosenv.2019.03.010

Liu, Z., and Phillips, J. (1991). "Comprehensive two-dimensional gas chromatography using an on-column thermal modulator interface," Journal of Chromatographic Science, 29, 227-231

Lu, X., Cai, J., Kong, H., Wu, M., Hua, R., Zhao, M., Liu, J., and Xu, G. (2003). "Analysis of cigarette smoke condensates by comprehensive two-dimensional gas chromatography/time-of-flight mass spectrometry acidic fraction," Analytical Chemistry 75(17), 4441-4451.

Mao, D., Lookman, R., Van de Weghe, H., Weltens, R. Vanermen, G. De Brucker, N., and Diels, L. (2009). "Combining HPLC-GCXGC, GCXGC/ToF-MS, and selected ecotoxicity assays for detailed monitoring of petroleum hydrocarbon degradation in soil and leaching water," Environmental Science \& Technology 43(20), 7651-7657. 
Martin, R., and Dell, J. (1978). Planning for Prescribed Burning in the Inland Northwest (General Technical Report No. PNW-76), USDA Forest Service Pacific Northwest Forest and Range Experiment Station, Portland, OR.

Matt, F., Dietenberger, M., and Weise, D. (2020). "Summative and ultimate analysis of live leaves from southern U.S. forest plants for use in fire modeling," Energy \& Fuels. 34(4), 4703-4720. DOI: 10.1021/acs.energyfuels.9b04107

Moore, R., Leitch, M., Arellano-ruiz, E., Smaglick, J., and Mann, D. (2015a). "Mountain pine beetle infestation: GCxGC-TOFMS and GC-MS of lodgepole pine (Pinus contorta) acetone extractives," in: 18th International Symposium on Wood, Fiber and Pulping Chemistry, Vienna, Austria, pp. 254-259.

Moore, R., Smaglick, J., Arellano-ruiz, E., Leitch, M., and Mann, D. (2015b). "Chemical polarity vs wood durability: The polarity of extractives on the durability of wood," in: 18th International Symposium on Wood, Fiber and Pulping Chemistry, Vienna, Austria, pp. 375-378.

Moore, R., Mann, D., Epstein, G., Hinkforth, B., Wagner, P., and Hyunji, J. (2017a). "Comparative characterization of extractives in Alaskan Yellow, Eastern Red, and Western Red Cedars," in: 19 $9^{\text {th }}$ International Symposium on Wood, Fiber and Pulping Chemistry, Porto Seguro, Bahia-Brazil.

Moore, R., Mann, D., and Yilgor, N. (2017b). "Comparative study of fungal deterioration in Liquidambar orientalis Mill Heartwood Extractives," in: 19 ${ }^{\text {th }}$ International Symposium on Wood, Fiber and Pulping Chemistry, Porto Seguro, Bahia-Brazil.

Moore, R., Mann, D., Epstein, G., Hinkforth, B., Wagner, P., and Hyunji, J. (2017c). "Characterization of extractives in durable and non-durable hardwoods: Black locust, Catalpa, and Honey mesquite," in: $19^{\text {th }}$ International Symposium on Wood, Fiber and Pulping Chemistry, Porto Seguro, Bahia-Brazil.

Moore, R. K., and Mann, D. (2020a). Classification of Chemicals in Black Locust Robinia pseudoacacia Wood and Bark (Report No. 99446), U.S. Department of Agriculture Forest Products Laboratory, Madison, WI.

Moore, R. K., and Mann, D. (2020b). Two-Dimensional Gas Chromatography Characterization of Saw Palmetto Serenoa repens Chemical Composition (Report No. 99480), U.S. Department of Agriculture Forest Products Laboratory, Madison, WI.

Moore, R. K., and Mann, D. (2020c). Investigation of Inkberry Ilex glabra L. Gray (Aquifoliaceae) Solvent Fractions using Two-Dimensional Gas Chromatography Technology (Report No. 99481), U.S. Department of Agriculture Forest Products Laboratory, Madison, WI.

Moore, R. K., Mann, D., Matt, F., Dietenberger, M., and Weise, D. (2020). Characterization of Fetterbush Lyonia lucida Liquid Extraction (Report No. 99444), U.S. Department of Agriculture Forest Products Laboratory, Madison, WI.

National Wildfire Coordinating Group (NWCG) (2018). NWCG Smoke Management Guide for Prescribed Fire (No. PMS 420-2), National Interagency Fire Center, Boise, ID.

Neves, D., Thunman, H., Matos, A., Tarelho, L., and Gómez-Barea, A. (2011). "Characterization and prediction of biomass pyrolysis products," Progress in Energy and Combustion Science 37, 611-630. DOI: 10.1016/j.pecs.2011.01.001

Norinaga, K., Yang, H., Tanaka, R., Appari, S. Iwanaga, K., Takashima, Y., Kudo, S., Shoji, T., and Hayash, J. (2014). "A mechanistic study on the reaction pathways 
leading to benzene and naphthalene in 5 cellulose vapor phase cracking," Biomass and Bioenergy 69, 144-154. DOI: 10.1016/j.biombioe.2014.07.008

Olson, M. R., Victoria Garcia, M., Robinson, M. A., Van Rooy, P., Dietenberger, M. A., Bergin, M., and Schauer, J. J. (2015). "Investigation of black and brown carbon multiple-wavelength-dependent light absorption from biomass and fossil fuel combustion source emissions," Journal of Geophysical Research: Atmospheres 120 (13) pgs 6682-6697. DOI: 10.1002/2014JD022970

Panic, O., and Gorecki, T. (2006). "Comprehensive two-dimensional gas chromatography (GCXGC) in environmental analysis and monitoring," Analytical Bioanalytical Chemistry 386, 1013-1023.

Pallozzi, E., Lusini, I., Cherubini, L., Hajiaghayeva, R., Ciccioli, P., and Calfapietra, C. (2018). "Differences between a deciduous and a conifer tree species in gaseous and particulate emissions from biomass burning," Environmental Pollution 234, 457-467. DOI: 10.1016/j.envpol.2017.11.080

Phillips, M. C., T. L. Myers, T. J. Johnson, and D. R. Weise. (2020). “In-Situ measurement of pyrolysis and combustion gases from biomass burning using swept wavelength external cavity quantum cascade lasers," Optics Express 28(6), 8680. DOI: $10.1364 / O E .386072$

Prichard, S., O’Neill, S., Eagle, P., and Andreu A., Drye, B., Dubowy, J., Urbanski, S. and Strand, T. (2020). "Wildland fire emission factors in North America: synthesis of existing data, measurement needs and management applications," International Journal of Wildland Fire 29, 132-147. DOI: 10.1071/WF19066

Prince, D. R., and Fletcher, T. H. (2014). "Differences in burning behavior of live and dead leaves - Part 1: Measurements," Combustion Science and Technology 186, 1844-1857. DOI: 10.1080/00102202.2014.923412

R Core Team (2020). R: A Language and Environment for Statistical Computing, R Foundation for Statistical Computing, Vienna, Austria.

Raven, P. H., Evert, R. F., and Curtis, H. (1981). Biology of Plants, $3^{\text {rd }}$ Ed., Worth Publishers, New York, N.Y.

Rein, G. (2013). "Smouldering fires and natural fuels," in: Fire Phenomena and the Earth System: An Interdisciplinary Guide to Fire Science, C. M. Belcher (ed.), John Wiley \& Sons, Hoboken, NJ, USA, pp. 15-33. DOI: 10.1002/9781118529539

Safdari, M.-S., Amini, E., Weise, D., and Fletcher, T. (2019). "Heating rate and temperature effects on pyrolysis products from live wildland fuels," Fuel 242, 295304. DOI: 10.1016/j.fuel.2019.01.040

Safdari, M.-S., Amini, E., Weise, D., and Fletcher, T. (2020). "Comparison of pyrolysis of live wildland fuels heated by radiation vs. convection," Fuel 268, 117342. DOI: 10.1016/j.fuel.2020.117342

Safdari, M.-S, Rahmati, M., Amini, E., Howarth, J., Berryhill, J., Dietenberger, M., Weise, D., and Fletcher, T. (2018). "Characterization of pyrolysis products from fast pyrolysis of live and dead vegetation native to the southern United States," Fuel 229, 151-166. DOI: 10.1016/j.fuel.2018.04.166

SAS Institute (2015). SAS/STAT® 14.1 User's Guide, Cary, NC, USA.

Scharko, N., Oeck, A., Myers, T., Tonkyn, R. Banach, C., Baker, S. Lincoln, E., Chong, J., Corcoran, B., Burke, G. et al. (2019a). "Gas-phase pyrolysis products emitted by prescribed fires in pine forests with a shrub understory in the southeastern United States," Atmospheric Chemistry and Physics 19(15), 9681-9698. DOI: 10.5194/acp19-9681-2019 
Scharko, N., Oeck, A., Myers, T., Tonkyn, R., Banach, C., Baker, S. Lincoln, E., Chong, J., Corcoran, B., et al. (2019b). "Identification of gas-phase pyrolysis products in a prescribed fire: First detections using infrared spectroscopy for naphthalene, methyl nitrite, allene, acrolein and acetaldehyde," Atmospheric Measurement Techniques 12(1), 763-776. DOI: 10.5194/amt-12-763-2019

Seeley, J. V., and Seeley, S. K. (2007). "Model for predicting comprehensive twodimensional gas chromatography retention times," Journal of Chromatography A 1172, 72-83. DOI: 10.1016/j.chroma.2007.09.058

Sekimoto, K., Koss, A. R., Gilman, J. B. Selimovic, V., Coggon, M. M., Zarzana, K. J., Yuan, B., Lerner, B. M., Brown, S. S., Warneke, C., Yokelson, R. J., Roberts, J.-M., and Gouw, J.-D. (2018). "High- and low-temperature pyrolysis profiles describe volatile organic compound emissions from western US wildfire fuels," Atmospheric Chemistry and Physics 18, 9263-9281. DOI: 10.5194/acp-18-9263-2018

Shafizadeh, F. (1968). "Pyrolysis and combustion of cellulosic materials," in: Advances in Carbohydrate Chemistry, Elsevier, Amsterdam, pp. 419-474.

Shellie, R., Marriott, P., and Chaintreau, A. (2004). "Quantitation of suspected allergens in fragrances (Part I): Evaluation of comprehensive two-dimensional gas chromatography for quality control," Flavour and Fragrance Journal 19(2), 91-98.

Shotorban, B., Yashwanth, B., Mahalingam, S. and Haring, D. (2018). "An investigation of pyrolysis and ignition of moist leaf-like fuel subject to convective heating," Combustion and Flame 190 (April), 25-35. DOI: 10.1016/j.combustflame.2017.11.008

Waldrop, T.-A., and Goodrick, S. (2012). Introduction to Prescribed Fires in Southern Ecosystems (Science Update No. SRS-054), USDA Forest Service, Southern Research Station, Asheville, NC, USA.

Wang, X., Sheng, L., and Yang, X. (2017). "Pyrolysis characteristics and pathways of protein, lipid and carbohydrate isolated from microalgae Nannochloropsis sp.," Bioresource Technology 229, 119-125.

Ward, D. E. (2001). "Combustion chemistry and smoke," in: Forest Fires: Behavior and Ecological Effects, E. A. Johnson and K. Miyanishi (eds.), Academic Press, San Diego, CA, pp. 55-77.

Weise, D. R., Jung, H., Palarea-Albaladejo, J., and Cocker, D. R. (2020a). "Compositional data analysis of smoke emissions from debris piles with low-density polyethylene," JAWMA 70, 834-845. DOI: 10.1080/10962247.2020.1784309

Weise, D. R., Palarea-Albaladejo, J., Johnson, T. J., and Jung, H. (2020b). “Analyzing wildland fire smoke emissions data using compositional data techniques," $J$. Geophys. Res. Atmos. 125, e2019JD032128. DOI: 10.1029/2019JD032128

Welthagen, W., Shellie, R., Ristow, M., Spranger, J., Zimmermann, R., and Fiehn, O. (2005). "Comprehensive two-dimensional gas chromatography/time of flight mass spectrometry GCXGC-TOF) for high resolution metabolomics: Biomarker discovery on spleen tissue extracts of obese NZO compared to lean C57BL/6 mice," Metabolomics 1, 57-65.

Yashwanth, B., Shotorban, B., Mahalingam, S., Lautenberger, C., and Weise, D. (2016). "A numerical investigation of the influence of radiation and moisture content on pyrolysis and ignition of a leaf-like fuel element," Combustion and Flame 163, 301316. DOI: 10.1016/j.combustflame.2015.10.006

Yokelson, R., Burling, I., Gilman, J., Warneke, C., Stockwell, C., de Gouw, J., Akagi, S., Urbanski, S., Veres, P., Roberts, J., Kuster, W., Reardon, J., Griffith, D., Johnson, T., 
Hosseini, S., Miller, J., Cocker III, D., Jung, H., and Weise, D. (2013). “Coupling field and laboratory measurements to estimate the emission factors of identified and unidentified trace gases for prescribed fires," Atmospheric Chemistry and Physics 13, 89-116. DOI: $10.5194 /$ acp-13-89-2013

Yokelson, R., Susott, R., Ward, D., Reardon, J., and Griffith, D. (1997). "Emissions from smoldering combustion of biomass measure by open-path Fourier transform infrared spectroscopy," Journal of Geophysical Research 102(14), 18865-18877.

Yokelson, R., Griffith, D., and Ward, D. (1996). "Open-path Fourier transform infrared studies of large-scale laboratory biomass fires," Journal of Geophysical Research 101(D15), 21067-21080. DOI: 10.1029/96JD01800

Zhao, C., Jiang, E., and Chen, A. (2017). "Volatile production from pyrolysis of cellulose, hemicellulose and lignin," Journal of the Energy Institute 90, 902-913.

Article submitted: August 2, 2021; Peer review completed: September 5, 2021; Revised version received: November 15, 2021; Accepted: November 16, 2021; Published:

December 10, 2021.

DOI: 10.15376/biores.17.1.862-889 


\section{APPENDIX}

\section{Supplementary}

Table S1. The Common Chemicals from the Seven Vegetation Foliage

\begin{tabular}{|c|c|c|c|c|c|c|c|c|c|c|c|c|c|c|c|c|c|c|c|}
\hline & \multirow[b]{2}{*}{ Name } & \multirow[b]{2}{*}{\begin{tabular}{|l|} 
Formula \\
\end{tabular}} & \multirow[b]{2}{*}{ FG } & \multirow{2}{*}{\begin{tabular}{|l|} 
R.T.1 \\
$(\mathrm{sec})$
\end{tabular}} & \multirow{2}{*}{\begin{tabular}{|l|} 
R.T.2 \\
(sec)
\end{tabular}} & \multicolumn{2}{|c|}{ Live Oak } & \multicolumn{2}{|c|}{ Saw Palmetto } & \multicolumn{2}{|c|}{ Longleaf Pine } & \multicolumn{2}{|c|}{ Swamp Bay } & \multicolumn{2}{|c|}{ Dwarf Palmetto } & \multicolumn{2}{|c|}{ Water Oak } & \multicolumn{2}{|c|}{ Yaupon } \\
\hline & & & & & & \begin{tabular}{|l|} 
PA\% \\
\end{tabular} & Similarity & PA\% & Similarity & PA\% & Similarity & PA\% & Similarity & PA\% & Similarity & PA\% & Similarity & PA\% & Similarity \\
\hline 1 & Nonanoic acid & $\mathrm{C}_{9} \mathrm{H}_{18} \mathrm{O}_{2}$ & Acid & 551 & 1.1 & 1.78 & 932 & 0.0472 & 926 & 0.019 & 910 & 0.0072 & 899 & 0.0502 & 920 & 0.0331 & 926 & 0.0181 & 904 \\
\hline 2 & Hexadecanoic acid & $\mathrm{C}_{16} \mathrm{H}_{32} \mathrm{O}_{2}$ & Acid & 1037 & 1.1 & 3.28 & 928 & 0.0081 & 902 & 0.025 & 913 & 0.0070 & 920 & 0.0349 & 918 & 0.0270 & 922 & 0.0164 & 917 \\
\hline 3 & (pyro)-catechol & $\mathrm{C}_{6} \mathrm{H}_{6} \mathrm{O}_{2}$ & Alcohol & 497 & 1.5 & 27.0 & 910 & 10.5 & 896 & 19.6 & 908 & 0.0340 & 826 & 34.9 & 902 & 18.6 & 908 & 1.06 & 908 \\
\hline 4 & Cresol & $\mathrm{C}_{7} \mathrm{H}_{8} \mathrm{O}$ & Alcohol & 389 & 1.3 & 0.122 & 930 & 0.283 & 928 & 1.12 & 948 & 0.0211 & 901 & 0.907 & 940 & 0.915 & 931 & 0.0262 & 942 \\
\hline 5 & Phenol & $\mathrm{C}_{6} \mathrm{H}_{6} \mathrm{O}$ & Alcohol & 308 & 1.3 & 0.034 & 858 & 0.423 & 924 & 5.18 & 968 & 0.230 & 946 & 0.754 & 941 & 7.71 & 964 & 0.143 & 949 \\
\hline 6 & (1-methylethyl)-Benzene & $\mathrm{C}_{9} \mathrm{H}_{12}$ & Alkene & 267 & 1.0 & 2.07 & 931 & 1.94 & 924 & 0.519 & 935 & 2.74 & 929 & 2.41 & 935 & 0.512 & 939 & 2.94 & 932 \\
\hline 7 & 2,3-dihydro-Benzofuran & $\mathrm{C}_{8} \mathrm{H}_{8} \mathrm{O}$ & Furan & 515 & 1.5 & 84.0 & 917 & 83.7 & 892 & 56.4 & 918 & 34.1 & 824 & 92.7 & 929 & 92.8 & 919 & 95.6 & 924 \\
\hline 8 & 4-hydroxy-4-methylpentane-2-one & $\mathrm{C}_{6} \mathrm{H}_{12} \mathrm{O}_{2}$ & Ketone & 204 & 0.33 & 11.8 & 959 & 20.0 & 960 & 39.3 & 955 & 14.5 & 951 & 21.1 & 960 & 5.25 & 965 & 25.2 & 957 \\
\hline 9 & 1,4:3,6-Dianhydro- $\alpha$-d-glucopyranose & $\mathrm{C}_{6} \mathrm{H}_{8} \mathrm{O}_{4}$ & Sugar & 510 & 1.9 & 0.0014 & 929 & 14.3 & 917 & 21.0 & 921 & 9.96 & 885 & 27.5 & 898 & 20.3 & 929 & 26.5 & 898 \\
\hline 10 & Anhydro - sugar & $\mathrm{C}_{5} \mathrm{H}_{8} \mathrm{O}_{4}$ & Sugar & 411 & 2.0 & 0.0011 & 916 & 7.39 & 920 & 38.3 & 921 & 13.0 & 910 & 9.24 & 890 & 24.4 & 930 & 21.0 & 926 \\
\hline 11 & 1,6-anhydro- $\beta$-D-Glucopyranose & \begin{tabular}{|l|}
$\mathrm{C}_{6} \mathrm{H}_{10} \mathrm{O}_{5}$ \\
\end{tabular} & Sugar & 726 & 2.2 & 0.0018 & 928 & 55.0 & 931 & 28.9 & 929 & 35.3 & 911 & 45.9 & 932 & 33.9 & 931 & 14.8 & 735 \\
\hline
\end{tabular}

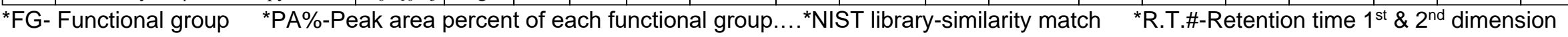




\section{bioresources.com}
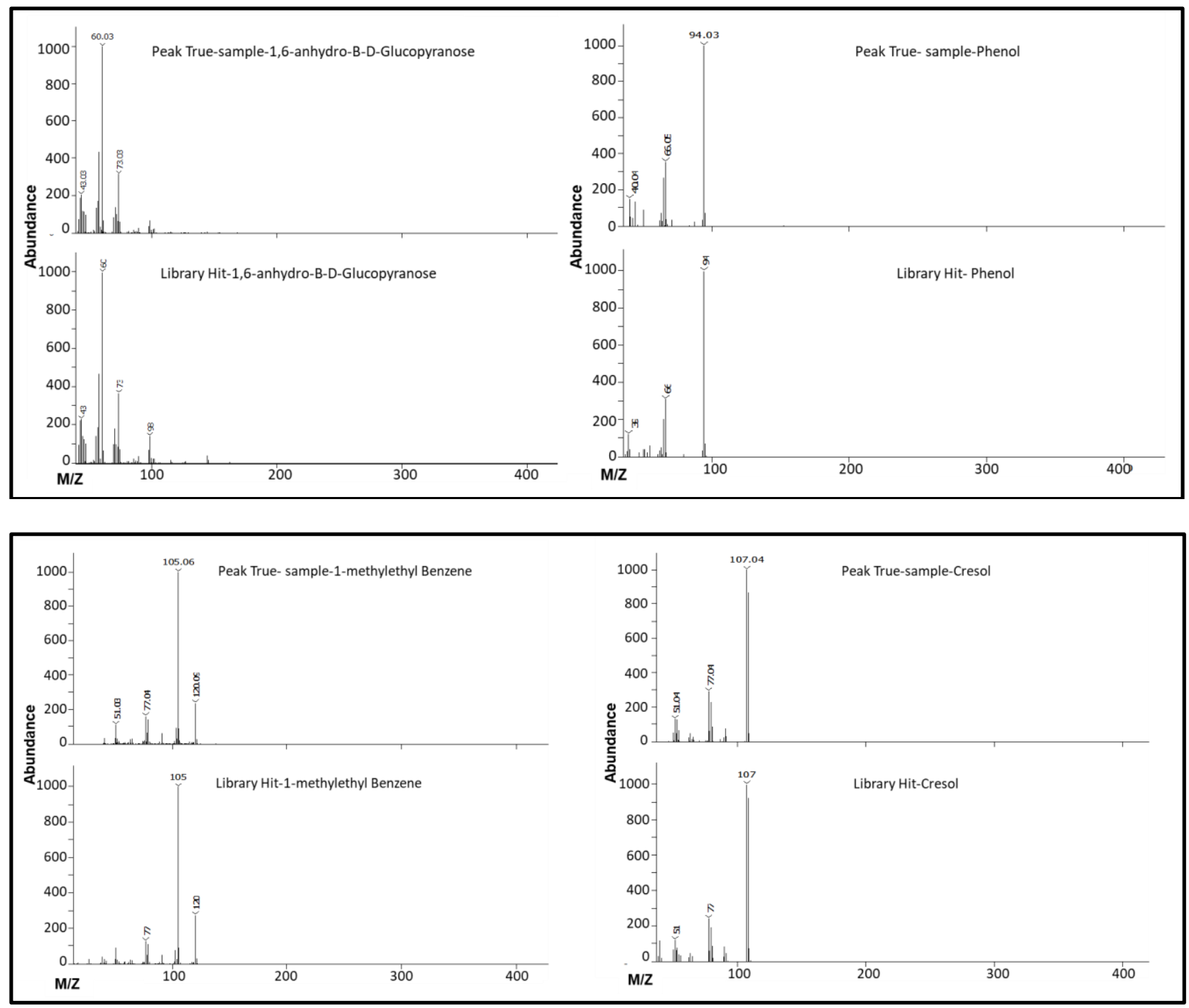

Fig. S1 (part 1). Common chemicals mass spectra of the seven-vegetation foliage 

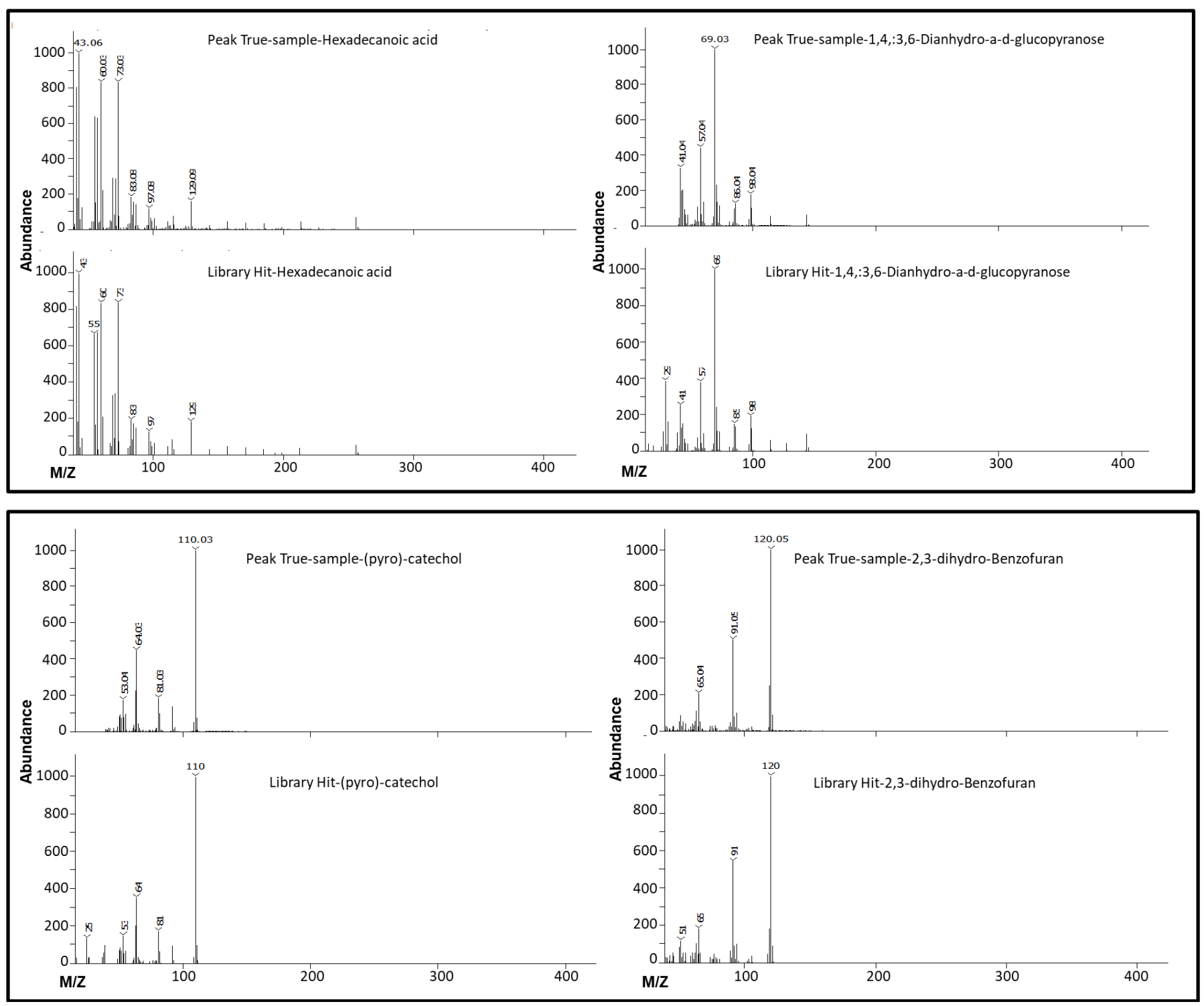

Fig. S1 (part 2). Common chemicals mass spectra of the seven-vegetation foliage 